Prepared in cooperation with the U.S. Fish and Wildlife Service

\title{
Monitoring Protocol Development and Assessment for Narrowly Endemic Toads in Nevada, 2018
}

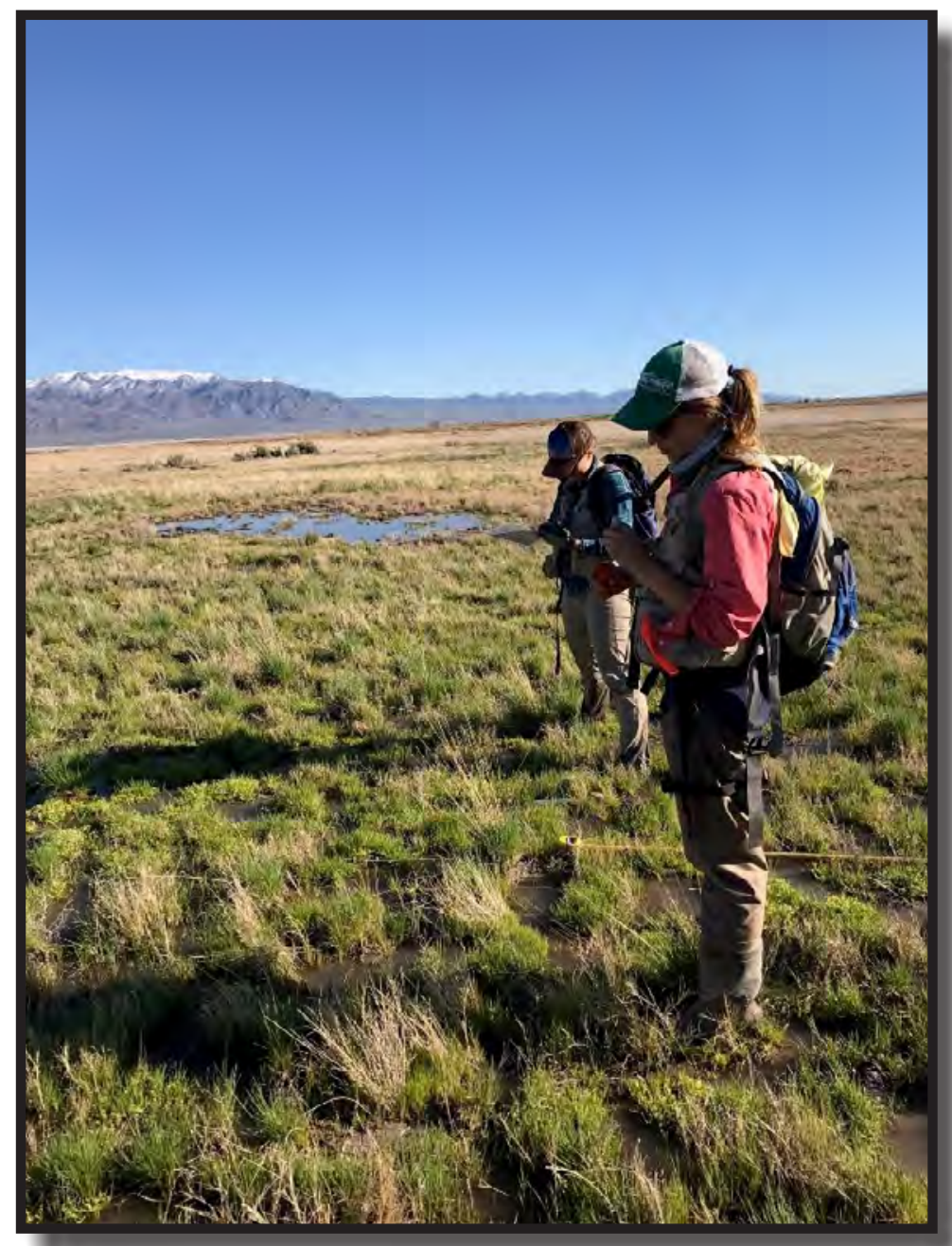

Open-File Report 2019-1067

U.S. Department of the Interior

U.S. Geological Survey 
Cover photo: Alexa Killion and Kelsey Ruehling establishing a grid cell for toad surveys in the Dixie Valley, Nevada, 2018. USGS photo taken by Patrick Kleeman. 


\section{Monitoring Protocol Development and Assessment for Narrowly Endemic Toads in Nevada, 2018}

By Brian J. Halstead, Patrick M. Kleeman, Adam Duarte, Jonathan P. Rose, Kris Urquhart, Chad Mellison, Kevin Guadalupe, Melanie Cota, Rachel Van Horne, Alexa Killion, and Kelsey Ruehling

Prepared in cooperation with the U.S. Fish and Wildlife Service

Open-File Report 2019-1067 


\title{
U.S. Department of the Interior DAVID BERNHARDT, Secretary
}

\author{
U.S. Geological Survey \\ James F. Reilly II, Director
}

U.S. Geological Survey, Reston, Virginia: 2019

For more information on the USGS - the Federal source for science about the Earth, its natural and living resources, natural hazards, and the environment-visit https://www.usgs.gov or call 1-888-ASK-USGS.

For an overview of USGS information products, including maps, imagery, and publications, visit https://store.usgs.gov.

Any use of trade, firm, or product names is for descriptive purposes only and does not imply endorsement by the U.S. Government.

Although this information product, for the most part, is in the public domain, it also may contain copyrighted materials as noted in the text. Permission to reproduce copyrighted items must be secured from the copyright owner.

Suggested citation:

Halstead, B.J., Kleeman, P.M., Duarte, A., Rose, J.P., Urquhart, K., Mellison, C., Guadalupe, K., Cota, M., Van Horne, R., Killion, A., and Ruehling, K., 2019, Monitoring protocol development and assessment for narrowly endemic toads in Nevada, 2018: U.S. Geological Survey Open-File Report 2019-1067, 28 p., https://doi.org/10.3133/ofr20191067. 


\section{Acknowledgments}

We thank the U.S. Fish and Wildlife Service (USFWS) and the U.S. Geological Survey (USGS) Amphibian Research and Monitoring Initiative (ARMI) for funding this study. The success of this study was greatly enhanced by participants in the project scoping and development meeting: Ann Bedlion (U.S. Navy), Sandra Brewer (Bureau of Land Management; BLM), Lee Ann Carranza (USFWS), Christopher Crookshanks (Nevada Department of Wildlife; NDOW), Robert Lovich (U.S. Navy), Jon Sjöberg (NDOW), Shawna Theisen (USFWS), Kimberly Tisdale (NDOW), and Donna Withers (U.S. Navy). Nathan Chelgren and Tritia Matsuda provided valuable reviews of this report. This research was conducted under Nevada Department of Wildlife Permit 39384. Any use of trade, product, or firm names is for descriptive purposes only and does not imply endorsement by the U.S. government. This is contribution 707 of the Amphibian Research and Monitoring Initiative (ARMI) of the U.S. Geological Survey. 


\section{Contents}

Abstract

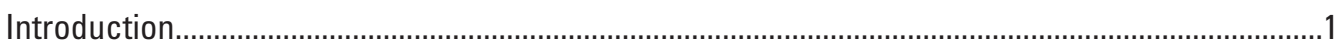

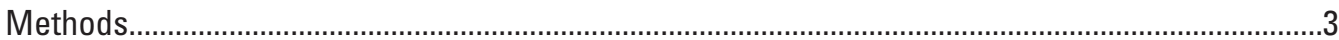

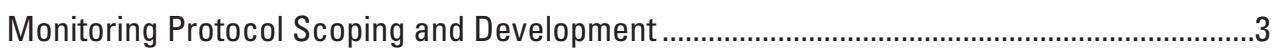

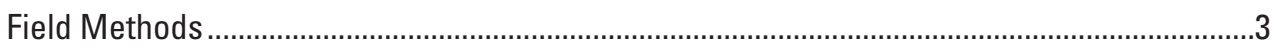

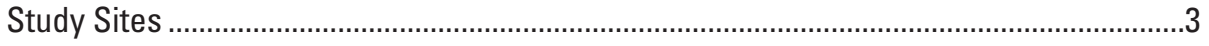

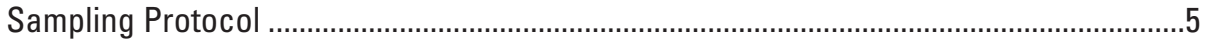

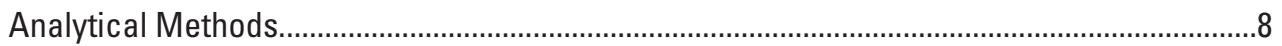

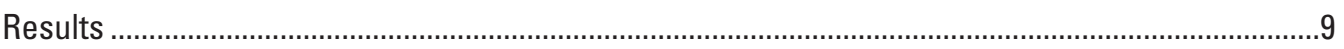

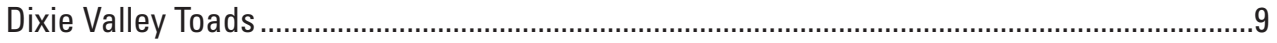

Toads in the Railroad Valley ...................................................................................................

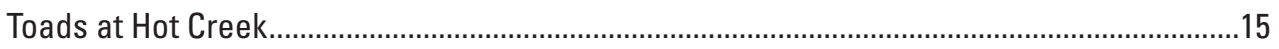

Effects of Survey Conditions on Cumulative Detection Probabilities ......................................18

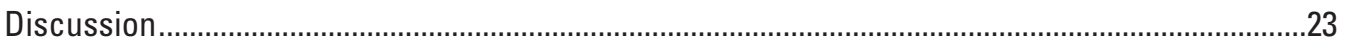

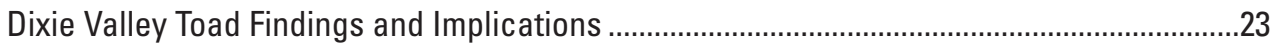

Railroad Valley Toad Findings and Implications ...............................................................2

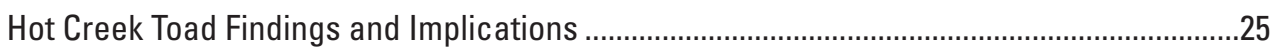

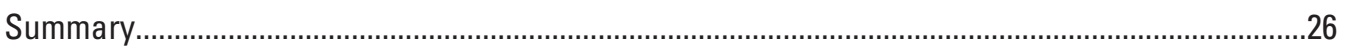

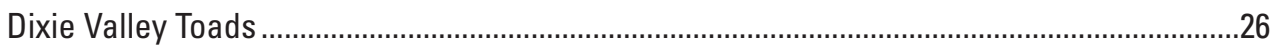

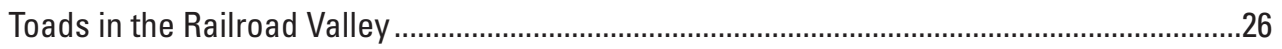

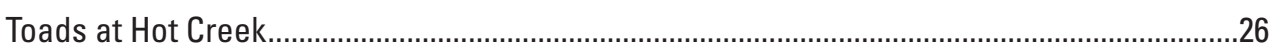

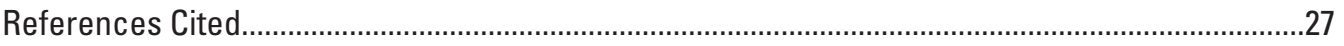

\section{Figures}

1. Map of the location of the Great Basin watershed in the western United States of America

2. Map of Dixie Meadows, Churchill County, Nevada, 2018, indicating sampling frame and locations of selected sample plots

3. Map of Railroad Valley, Nye County, Nevada, 2018, indicating sampling frame and locations of selected sample plots

4. Map of Hot Creek, Nye County, Nevada, 2018, indicating sampling frame and locations of selected sample plots

5. Graph showing frequency distribution of the number of post-metamorphic Dixie Valley Toads detected per survey in Dixie Meadows, Churchill County, Nevada, 2018

6. Graphs showing probability of occurrence of adult Dixie Valley toads in relation to survey period and water temperature in the Dixie Valley, Churchill County, Nevada, 2018

7. Graphs showing probability of reproduction of Dixie Valley toads in occupied plots in relation to percent of plot surface covered by water and water temperature in the Dixie Valley, Churchill County, Nevada, 2018

8. Graphs showing detection probability of adult Dixie Valley toads in relation to survey period, survey duration, and percent emergent vegetation in the Dixie Valley, Churchill County, Nevada, 2018 
9. Graphs showing detection probability of larval Dixie Valley toads in relation to time of survey, survey duration, and percent emergent vegetation in the Dixie Valley, Churchill County, Nevada, 2018

10. Graph showing detection probability of adult western toads in the Railroad Valley, Nye County, Nevada, 2018, in relation to survey duration.

11. Graphs showing detection probability of larval western toads in the Railroad Valley, Nye County, Nevada, 2018, in relation to time of survey and survey duration.....15

12. Graphs showing probability of reproduction of western toads at Hot Creek, Nye County, Nevada, 2018, in occupied plots in relation to percent of plot surface covered by water and percent emergent vegetation.

13. Graphs showing detection probability of adult western toads at Hot Creek, Nye County, Nevada, 2018, in relation to time of survey and survey duration.

14. Graph showing detection probability of larval western toads at Hot Creek, Nye County, Nevada, 2018, in relation to percent emergent vegetation

15. Graphs showing cumulative detection probabilities of adult Dixie Valley toads based on survey month, survey duration, and number of independent surveys

16. Graphs showing cumulative detection probabilities of larval Dixie Valley toads based on survey month, survey duration, and number of independent surveys

17. Graphs showing cumulative detection probabilities of adult western toads in the Railroad Valley, Nevada, based on survey duration and number of independent surveys

18. Graphs showing cumulative detection probabilities of larval western toads in the Railroad Valley, Nevada, based on survey duration and number of independent surveys

19. Graphs showing cumulative detection probabilities of adult western toads at Hot Creek, Nevada, based on time of day, survey duration, and number of independent surveys

20. Graphs showing cumulative detection probabilities of larval western toads at Hot Creek, Nevada, based on emergent vegetation cover and number of independent surveys

\section{Tables}

1. Posterior inclusion probabilities for variables affecting probability of occurrence of adults and probability of reproduction of Dixie Valley toads in the Dixie Valley, Churchill County, Nevada, 2018.

2. Posterior inclusion probabilities for variables affecting detection probability of adult and larval Dixie Valley toads in the Dixie Valley, Churchill County, Nevada, 2018.

3. Posterior inclusion probabilities for variables affecting detection probability of adult and larval western toads in the Railroad Valley, Nye County, Nevada, 2018

4. Posterior inclusion probabilities for variables affecting probability of adult occurrence and probability of reproduction of western toads at Hot Creek, Nye County, Nevada, 2018.

5. Posterior inclusion probabilities for variables affecting detection probability of adult and larval western toads at Hot Creek, Nye County, Nevada, 2018 


\section{Conversion Factors}

International System of Units to U.S. customary units

\begin{tabular}{lcl}
\hline \multicolumn{1}{c}{ Multiply } & By & \multicolumn{1}{c}{ To obtain } \\
\hline & Length & \\
\hline centimeter $(\mathrm{cm})$ & 0.3937 & inch (in.) \\
meter (m) & 3.281 & foot (ft) \\
meter (m) & 1.094 & yard (yd) \\
\hline & Area & \\
\hline hectare (ha) & 2.471 & acre \\
hectare (ha) & 0.003861 & square mile (mi2) \\
\hline & Mass & \\
\hline gram (g) & 0.03527 & ounce, avoirdupois (oz) \\
\hline
\end{tabular}

Temperature in degrees Celsius $\left({ }^{\circ} \mathrm{C}\right)$ may be converted to degrees Fahrenheit $\left({ }^{\circ} \mathrm{F}\right)$ as

$$
{ }^{\circ} \mathrm{F}=\left(1.8 \times{ }^{\circ} \mathrm{C}\right)+32 .
$$

\section{Abbreviations}

$\begin{array}{ll}\text { BLM } & \text { Bureau of Land Management } \\ \text { CMR } & \text { capture-mark-recapture } \\ \text { GPS } & \text { Global Positioning System } \\ \text { GRTS } & \text { generalized random tessellation stratified } \\ \text { IQR } & \text { interquartile range } \\ \text { JAGS } & \text { Just Another Gibbs Sampler } \\ \text { MCMC } & \text { Markov-chain Monte Carlo } \\ \text { NDOW } & \text { Nevada Department of Wildlife } \\ \text { OSU } & \text { Oregon State University } \\ \text { SD } & \text { standard deviation } \\ \text { USFS } & \text { U.S. Forest Service } \\ \text { USFWS } & \text { U.S. Fish and Wildlife Service } \\ \text { USGS } & \text { U.S. Geological Survey }\end{array}$




\title{
Monitoring Protocol Development and Assessment for Narrowly Endemic Toads in Nevada, 2018
}

\author{
By Brian J. Halstead, ${ }^{1}$ Patrick M. Kleeman, ${ }^{1}$ Adam Duarte, ${ }^{2}$ Jonathan P. Rose, ${ }^{1}$ Kris Urquhart, ${ }^{3}$ Chad Mellison, ${ }^{4}$ \\ Kevin Guadalupe, ${ }^{3}$ Melanie Cota, ${ }^{5}$ Rachel Van Horne,${ }^{6}$ Alexa Killion, ${ }^{1}$ and Kelsey Ruehling ${ }^{1}$
}

\section{Abstract}

Several species and subspecies of toads are endemic to small spring systems in the Great Basin, and their restricted ranges and habitat extent make them vulnerable to environmental perturbations. Very little is known about several of these toad populations, so a group of stakeholders including the U.S. Geological Survey, U.S. Fish and Wildlife Service, Bureau of Land Management, Nevada Department of Wildlife, the U.S. Navy, U.S. Forest Service, and Oregon State University met to discuss information needs on these populations and to develop a monitoring protocol that would detect population changes over time. In cooperation with the U.S. Fish and Wildlife Service, the U.S. Geological Survey implemented the proposed survey protocol, a multi-state occupancy design, for three sites: Dixie Valley, Railroad Valley, and Hot Creek, to evaluate its ease of implementation and effectiveness. We found that the multi-state occupancy protocol worked well in the Dixie Valley and, with some refinement, would likely work well in the Railroad Valley. We suggest that capture-mark-recapture of adults might be a more effective approach at Hot Creek. For most life stages of most populations, detection probabilities were positively related to survey duration up to 20 minutes, and the best time of day to conduct surveys varied by life stage and population. We make population-specific suggestions for the number of surveys and their timing and duration. Annual surveys using the suggested survey protocols will likely allow estimation of trends in the proportion of area of each population existing in different population states (occupied, occupied with evidence of reproduction, and unoccupied) and in most cases can be readily implemented with minimal training or handling of toads.

\footnotetext{
${ }^{1}$ U.S. Geological Survey

${ }^{2}$ Oregon State University

${ }^{3}$ Nevada Department of Wildlife

${ }^{4}$ U.S. Fish and Wildlife Service

${ }^{5}$ Bureau of Land Management

${ }^{6}$ U.S. Forest Service
}

\section{Introduction}

The Great Basin, which is in the western U.S.A. and spans nearly all of Nevada and adjacent portions of neighboring states (California, Idaho, Oregon, and Utah; fig. 1), is one of the most arid parts of North America. Spring systems in the region are a lifeline for many species, and these springs provide refugia for aquatic and semi-aquatic taxa, including fishes, amphibians, and invertebrates. Because of the inhospitable climate and sometimes long distances between spring systems, endemism of aquatic taxa inhabiting springs is high. For example, several pupfish (Cyprinodon spp.) occur in the Great Basin and have very small ranges; these fishes are often restricted to single spring systems.

Like spring fishes, surface water is essential for most amphibians, and many amphibians require standing water of sufficient duration to reproduce and complete their life cycles. Recently, genetic and morphological examination of the western toad complex (Anaxyrus $[=$ Bufo] boreas) has uncovered cryptic species and subspecies associated with isolated springs in the Great Basin (Forrest and others, 2017; Gordon and others, 2017). Because these populations are geographically isolated and genetically and morphologically distinct, they are being considered for treatment as separate management units.

Managing wildlife populations requires that their distribution, abundance, or both be evaluated and monitored to allow resource managers to identify trends and evaluate the effects of management decisions on populations. Because individuals and entire populations can go undetected, monitoring protocols must be carefully designed to avoid drawing biased and potentially misleading conclusions from monitoring data. For example, a population could erroneously be thought to be increasing or stable, even if abundance is declining, if detectability increases over time. Identifying and evaluating monitoring strategies that account for imperfect detection and measure population characteristics important to resource managers is a vital component of any wildlife management program. 




Figure 1. Location of the Great Basin watershed in the western United States of America. Study sites are indicated with circles; counties in which research was conducted are labeled. 
In cooperation with the U.S. Fish and Wildlife Service, our primary goal for this study was to develop, implement, and evaluate a monitoring protocol for narrowly endemic toads in the Great Basin. Within this larger goal, we had several objectives, including the following:

1. To identify population characteristics that stakeholders agree represent the health of the population and any changes to it.

2. To develop a monitoring protocol to measure these population characteristics.

3. To implement the monitoring protocol and evaluate its ease of implementation in the field.

4. To evaluate the results of monitoring, including assessment of variables affecting detection probabilities and the status of the population.

5. To suggest refinements to the monitoring protocol based on these results.

\section{Methods}

\section{Monitoring Protocol Scoping and Development}

Stakeholders interested in or responsible for management of narrowly endemic Great Basin toad populations met for 2 days in Reno, Nevada, in February 2018. Participants included the Nevada Department of Wildlife (NDOW), the Bureau of Land Management (BLM), the U.S. Navy, the U.S. Fish and Wildlife Service (USFWS), the U.S. Forest Service (USFS), the U.S. Geological Survey (USGS), and Oregon State University (OSU). The first day of the meeting included a field visit to Dixie Meadows (a small portion of the Dixie Valley containing springs and the hydric and mesic areas created by their outflow), where personnel experienced with Dixie Valley toads (herein considered Anaxyrus williamsi, with the acknowledgment that the taxonomic status of this distinct management unit of western toads is unresolved) provided a site tour and described toad ecology, past monitoring efforts, and lessons learned from previous work. The second day involved a group discussion by all stakeholders to review background information on the toads in the Dixie Valley, Hot Creek, and the Railroad Valley; define the scope of the monitoring problem for each population and potential logistical constraints to monitoring; and identify and structure the objectives of a monitoring program.

Several key outcomes resulted from the meeting. Much of the discussion focused on measuring population state or health of toads in the Dixie Valley. Although capture-markrecapture (CMR) methods had been attempted for Dixie Valley toads, recapture rates were very low. In addition, marking toads requires training and equipment, and implementation of a monitoring plan focusing on absolute abundance was deemed infeasible and, for the time being, unnecessary. Instead, the group agreed that the proportion of area used for reproduction (as evidenced by pre-metamorphic life stages), occupied by a large number of adults (to be determined based on the distribution of counts), and occupied by the species in general (in other words, one or few adults) was a reasonable metric of population health. The group discussed the assumption of closure (no change in state for a sampled unit between surveys) relative to sample unit size and timing of surveys. Violation of the closure assumption would provide estimates of use of areas, rather than "occupancy." Because the monitoring protocol is intended to detect patterns and changes in occurrence, rather than use, closure of cells to movement of toads between surveys was given strong consideration in sampling design. These data could be obtained by detection-nondetection surveys on a random selection of plots and, if repeated annually, would provide information on changes in the proportion of area occupied by adults and pre-metamorphic life stages over time. In addition to trends over time, explaining the distribution of population states as a function of water temperature, availability, and quality and vegetation characteristics was important.

Attendees thought that these metrics would be useful for toad populations at Railroad Valley and Hot Creek as well. Because these populations have not been studied as intensively, obtaining a baseline understanding of toad distribution was deemed of primary importance for these populations.

\section{Field Methods}

\section{Study Sites}

We conducted our study at three sites corresponding to locations of narrowly endemic species or subspecies of toads (A. williamsi and two $A$. boreas ssp.). We conducted studies of Dixie Valley toads at Dixie Meadows, Churchill County, Nevada (fig. 2). Dixie Meadows is a mixture of Great Basin desert scrub, grasslands, and wetlands associated with springs of various discharge temperatures. The site is managed by the U.S. Navy and BLM and is within an active grazing allotment. Geothermal energy development also occurs on and adjacent to the site. We conducted our study across the known range of Dixie Valley toads, encompassing 144.5 hectares (ha) of wetlands and immediately adjacent grassland and scrub. To obtain a probabilistic sample of the site, we divided the site into five strata defined by different springs and overlaid a 20 meter $(\mathrm{m}) \times 20 \mathrm{~m}$ grid over each stratum (fig. 2 ). We then selected cells from the grid using generalized random tessellation stratified (GRTS) sampling (Stevens and Olsen, 2004) with a minimum of three cells per stratum using the $R$ package "spsurvey" (Kincaid and Olsen, 2016). 


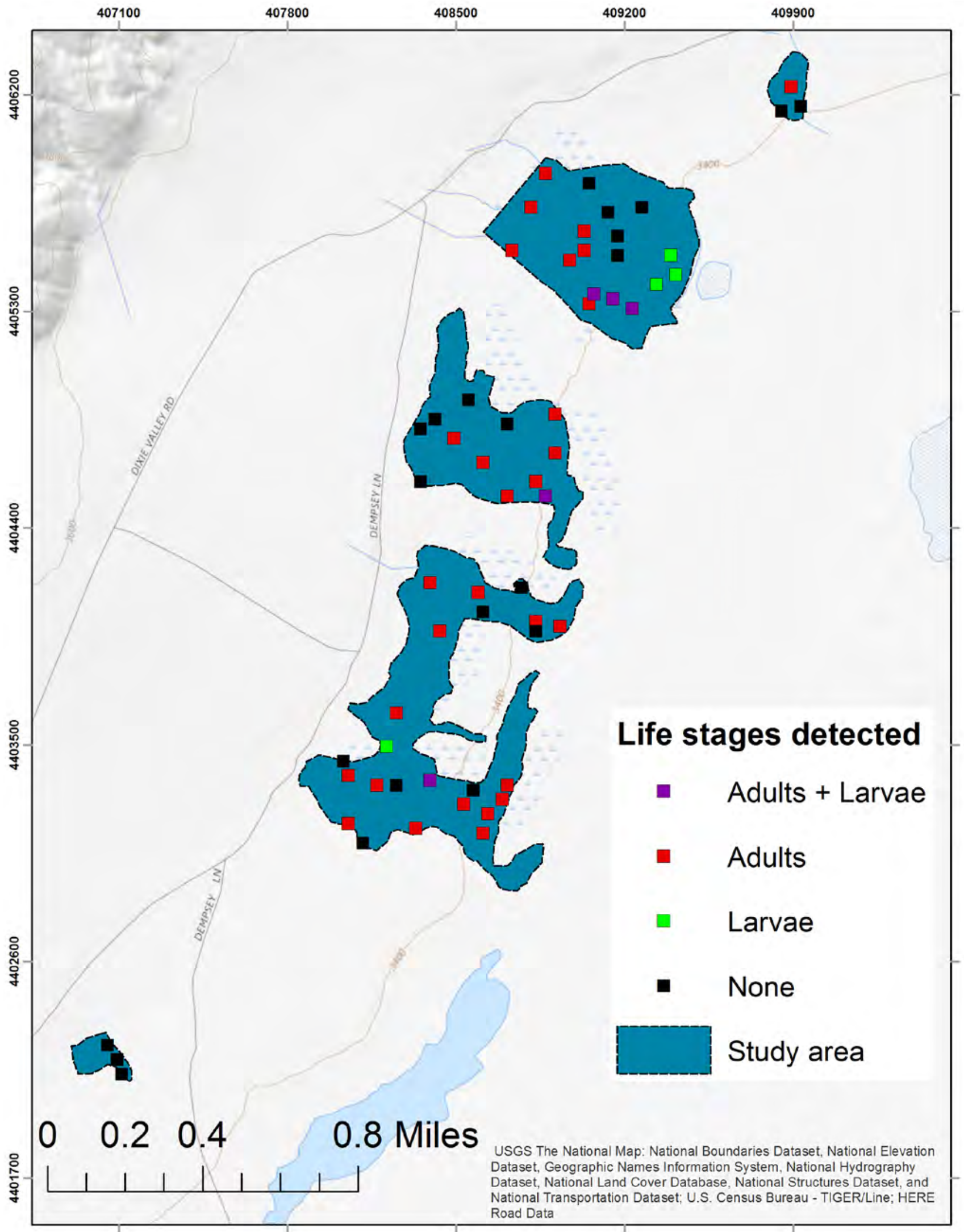

Figure 2. Dixie Meadows, Churchill County, Nevada, 2018, indicating sampling frame and locations of selected sample plots. Symbols on map are larger than actual plots. Coordinates at tick marks are Universal Transverse Mercator (UTM) North American Datum (NAD) 1983, Zone 11. 
We studied populations of western toads at two sites in Nye County, Nevada: Railroad Valley (fig. 3) and Hot Creek (fig. 4). The Railroad Valley site, like Dixie Meadows, was a mixture of Great Basin desert scrub, grasslands, wetlands, and groves of Russian olive (Elaeagnus angustifolia) associated with springs of various discharge temperatures. A historical homestead and some planted trees also occur at the site. Railroad Valley is managed by BLM and the State of Nevada. We conducted our study on approximately 198 ha appearing to have surface water at least part of the year on satellite imagery and under public ownership. As with Dixie Meadows, we overlaid a $20 \mathrm{~m} \times 20 \mathrm{~m}$ grid over each stratum and selected cells from the grid using GRTS sampling with a minimum of two cells per stratum (fig. 3).

Hot Creek included a creek, springs, and associated wetlands in a matrix of Great Basin desert scrub. The site was unique in that the Hot Creek watershed is within two wild horse management areas. Wild horses grazed and drank within our study area, and herbaceous vegetation at the site was much shorter than at Dixie Meadows and Railroad Valley. We conducted our study on approximately 13 ha appearing to have surface water at least part of the year on satellite imagery. We were notified by a rancher that a portion of our sampled area was on his private property; although he permitted sampling, we discontinued sampling of the privately owned locations because they were counter-indicated to be included in a longterm monitoring strategy at this time. The public portion of the site was managed by BLM and USFS. As for the other sites, we overlaid a $20 \mathrm{~m} \times 20 \mathrm{~m}$ grid over the site and selected cells from the grid using GRTS sampling. In addition to the selected sample plots, we also conducted visual encounter surveys of nearby potential habitat.

\section{Sampling Protocol}

For the Dixie Valley toad, we established the locations and boundaries of sampled grid cells (hereafter, plots) by finding each plot's centroid with GPS (Bad Elf, Tariffville, Connecticut, U.S.A.), marking the centroid with a capped piece of rebar driven into the ground, and using a measuring tape and compass to mark the corners of each $20 \mathrm{~m} \times 20 \mathrm{~m}$ plot with wire flags. To increase efficiency of establishing plots at Railroad Valley and Hot Creek, we located and marked plot centroids, but we surveyed circular plots with a $10-\mathrm{m}$ radius to reduce setup time by eliminating the need to establish plot corners. We initiated diurnal surveys after 10:00 and nocturnal surveys 1 hour after sunset. We surveyed each plot by walking through it systematically and searching for toads, using a $10-\mathrm{m}$ rope tethered to the rebar placed at the centroid at Hot Creek and Railroad Valley to assist with locating plot boundaries. Because habitat varied in its complexity and ability to provide cover for toads, we set a lower limit of 5 minutes and an upper limit of 20 minutes for the duration of searching on each plot. We recorded the number of each life stage of all herpetofauna observed in each survey. We also recorded survey conditions (date, time, survey duration, cloud cover, wind speed, air temperature, water temperature) and measured plot characteristics (degree of alteration, macrohabitat composition [for example, pond, stream, grassland or meadow, scrubland, and spring], percent of the surface area of the plot that was wetted, mean depth of water in the plot, maximum depth of water in the plot, water flow rate, water clarity [ $1=$ clear to $5=<1$ centimeter visibility], percent of plot shaded, percent emergent vegetation, percent floating vegetation, and salinity [with a refractometer; at only a subset of plots and surveys]) at each survey. We surveyed for Dixie Valley toads in 60 out of 3,612 possible plots between April 21 and 23, 2018, and again between May 14 and 21, 2018, and surveyed each plot 1-3 times in April and 1-4 times in May, for a total of 2-5 total surveys per plot. At Railroad Valley, we surveyed 60 out of 4,956 possible plots 1-3 times each between May 30 and June 3, 2018. At Hot Creek, we surveyed 51 out of 333 possible plots 2-4 times each between May 1 and 6, 2018. 


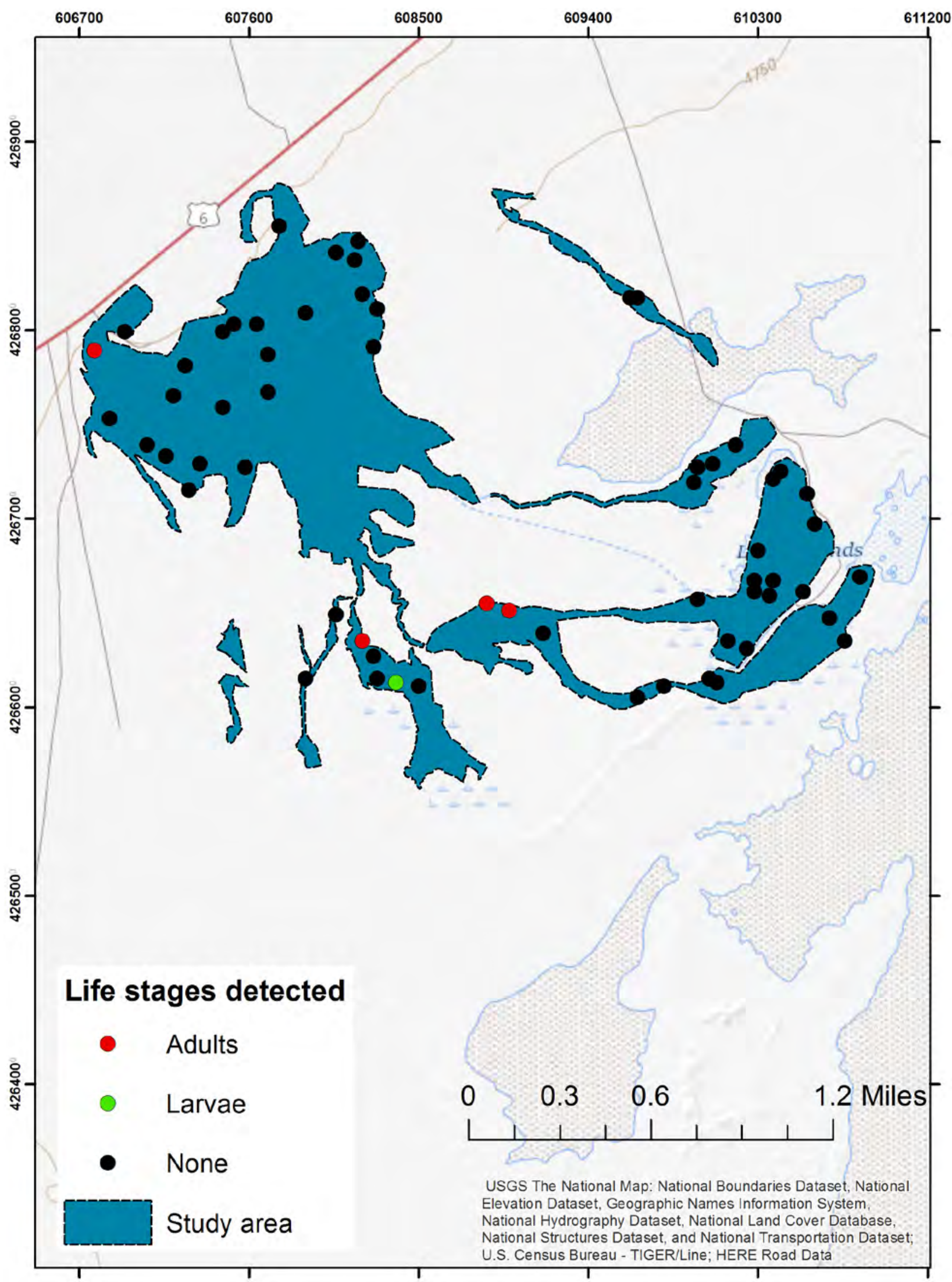

Figure 3. Railroad Valley, Nye County, Nevada, 2018, indicating sampling frame and locations of selected sample plots. Symbols are larger than actual plots. Coordinates at tick marks are Universal Transverse Mercator (UTM) North American Datum (NAD) 1983, Zone 11. 


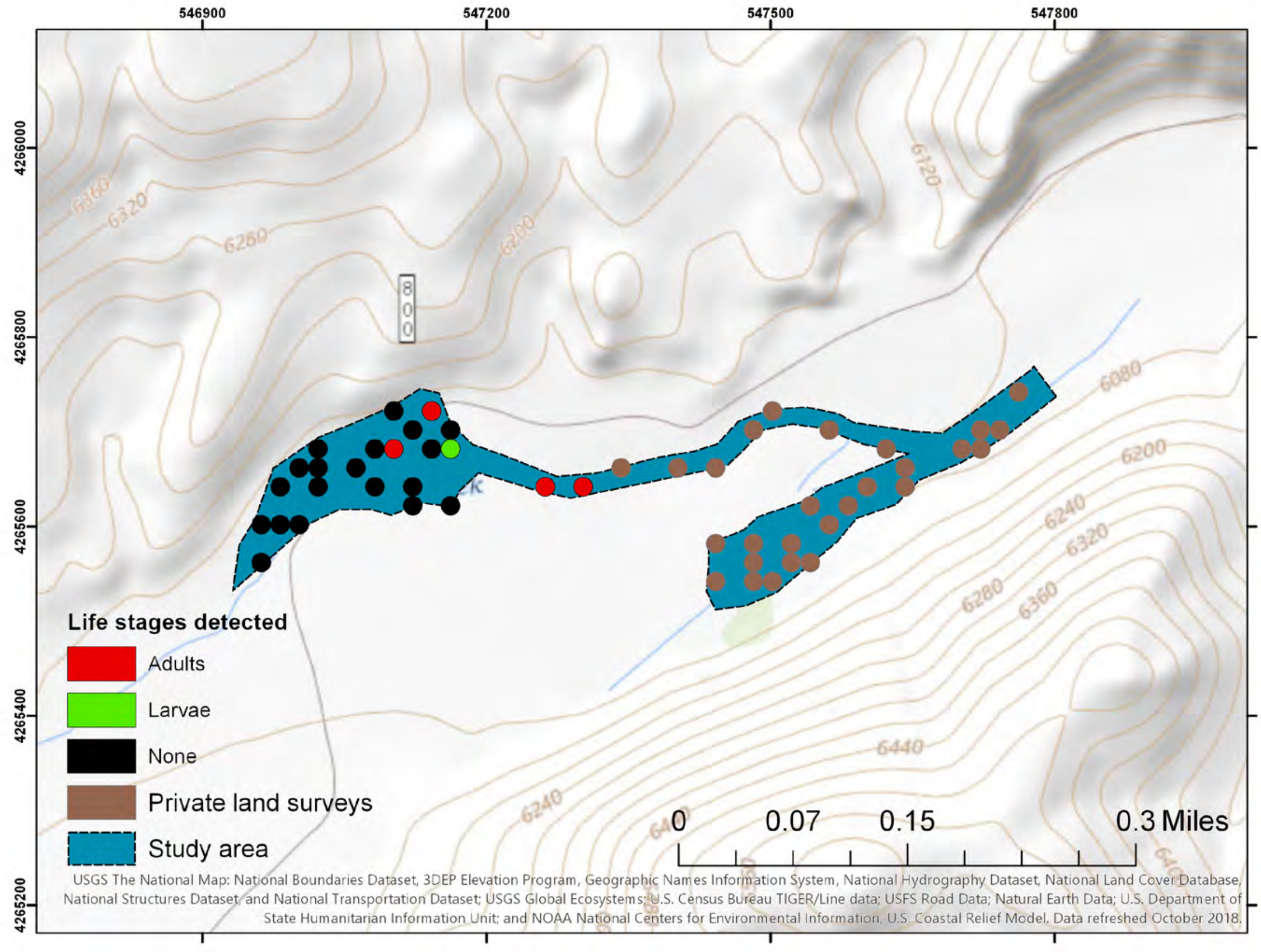

Figure 4. Hot Creek, Nye County, Nevada, 2018, indicating sampling frame and locations of selected sample plots. Coordinates at tick marks are Universal Transverse Mercator (UTM) North American Datum (NAD) 1983, Zone 11. 


\section{Analytical Methods}

We analyzed the data for all three sites using multistate occupancy models (Nichols and others, 2007; Kéry and Schaub, 2012). We included three states for occurrence in a grid cell: (1) unoccupied, (2) occupied by the species without reproduction, and (3) occupied by the species and with pre-metamorphic life stages as evidence of reproduction. Occupancy states were defined as unoccupied $=(1-\psi)$, occupied without reproduction $=\psi \times(1-r)$, and occupied with reproduction $=\psi \times r$, where $\psi$ is the probability of occurrence by adult toads, and $r$ is the probability that a plot occupied by adult toads is used for reproduction (in other words, used by tadpoles). We did not use the four-state model suggested in the meeting because most plots with toad detections had only one or two toads detected in the plot, and no clear breaks existed to distinguish plots with abundant toads from those simply occupied by toads (fig. 5). Our states for detection were (1) no individuals detected, (2) at least one adult detected but no pre-metamorphic life stages detected, and (3) pre-metamorphic life stages detected (regardless of whether adults also were detected). The detection states, conditional on the occupancy states, were defined as

\begin{tabular}{|c|c|c|c|}
\hline & Not detected & $\begin{array}{c}\text { Only } \\
\text { adults } \\
\text { detected }\end{array}$ & $\begin{array}{c}\text { Larvae } \\
\text { detected }\end{array}$ \\
\hline Unoccupied & 1 & 0 & 0 \\
\hline Occupied & $1-p_{2}$ & $p_{2}$ & 0 \\
\hline $\begin{array}{l}\text { Occupied and used } \\
\text { for reproduction }\end{array}$ & $\left(1-p_{2}\right)\left(1-p_{3}\right)$ & $p_{2}\left(1-p_{3}\right)$ & $p_{3}$ \\
\hline
\end{tabular}

where $p_{2}$ is the probability of detection for adult toads, and $p_{3}$ is the probability of detecting toad tadpoles.

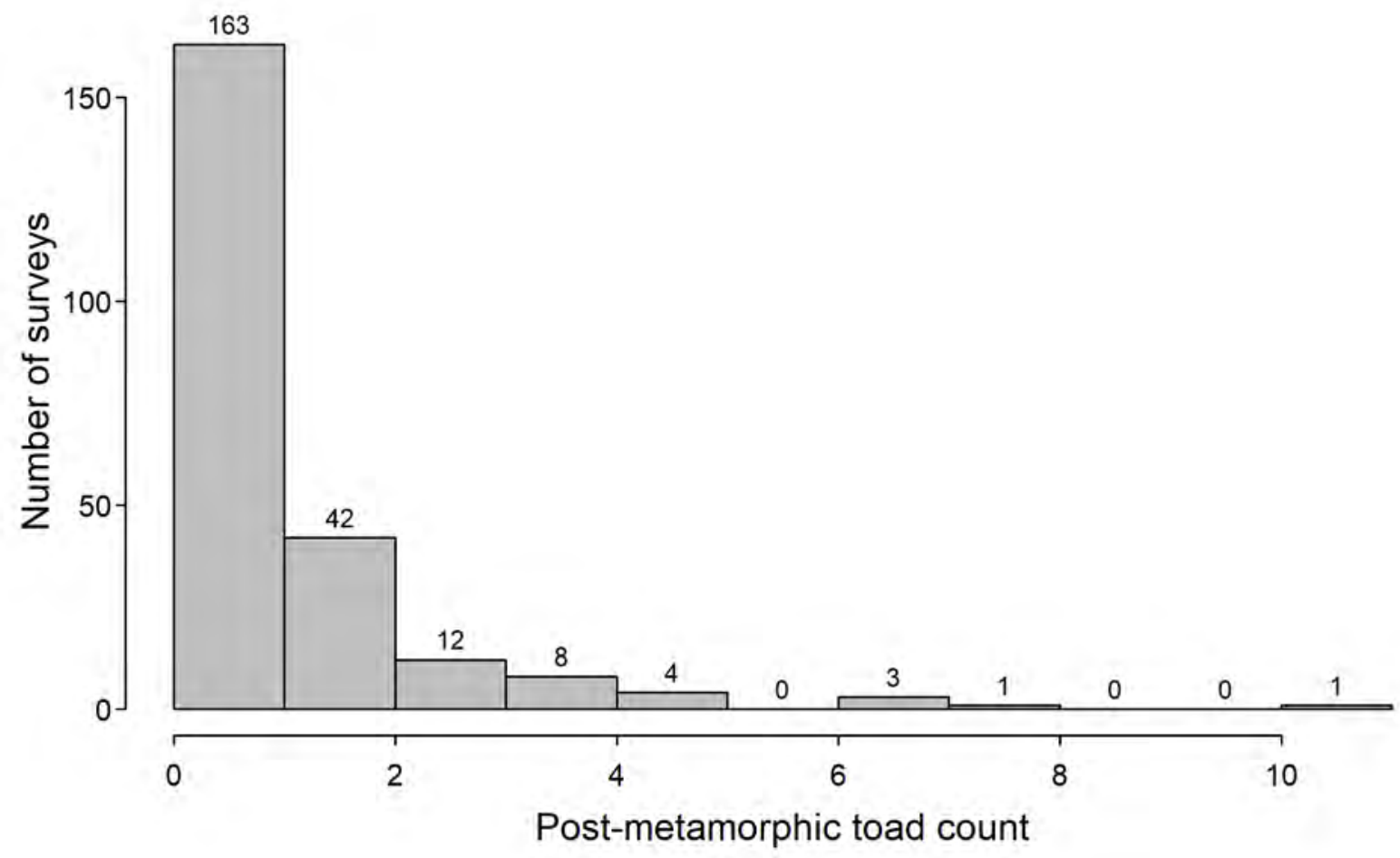

Figure 5. Frequency distribution of the number of post-metamorphic Dixie Valley Toads detected per survey in Dixie Meadows, Churchill County, Nevada, 2018. 
Because we sampled Dixie Valley toads at two disjunct time periods, we modeled April and May separately, but in the same model, by treating detection histories for each plot as independent for each month (in other words, the same plot appeared as two separate rows of data) and using month of sampling as a factor in the model. This allowed the habitat characteristics used in each plot to change from one month to the other, while allowing the influence of variables on detection and occurrence probabilities to be shared across the entire dataset. We used Bayesian variable selection techniques (Kuo and Mallick, 1998), whereby model coefficients are multiplied by an indicator variable that takes a value of 0 or 1 and acts as a switch to turn the effects of different variables on and off. To make the effects of variables measured on different scales comparable, allow for appropriate model selection, and improve convergence and mixing of the Markov-chain Monte Carlo (MCMC) algorithm, we centered and standardized (to mean $=0$ and standard deviation $[\mathrm{SD}]=1$ ) all continuous variables. For $\psi$ and $r$, we examined linear effects of the percent of the cell's surface area covered by water and the mean water depth, and linear and quadratic effects of percent emergent vegetation and water temperature. At Dixie Valley, we also included an effect of month to estimate $\psi$ and $r$ separately for April and May. At Railroad Valley, we had very few detections, and many sampled locations were dry. At this site, we therefore only considered percent of plot surface wetted as a covariate on $\psi$ and $r$. For $p_{2}$ and $p_{3}$, we examined survey duration, air temperature, time of day $(0=$ diurnal, 1 = nocturnal), percent emergent vegetation, and a random observer effect. For Dixie Valley toads, we also included an effect of month of sampling on detection probability. Because we had few detections of western toads at Railroad Valley and only two observers, we only considered survey duration, air temperature, and time of day as covariates on detection with no observer effect.

We used vague priors on all parameters. We specified priors for mean detection and occupancy probabilities and probability of reproduction as Beta $($ alpha $=1$, beta $=1)$ (italics indicate a probability distribution) and transformed them to intercepts on the logit-scale. We used hierarchical shrinkage priors on model coefficients to avoid prior sensitivity issues with regard to model selection (Link and Barker, 2010; Kruschke, 2015). We specified these as $t$ (location $\left.=0, S D=\sigma_{\text {coef }} d f=1\right)$, where $\sigma_{\text {coef }} \sim$ halfCauchy(1), specified as $t(0,1,1)$ truncated at 0 (Gelman, 2006). We gave indicator variables Bernoulli $(p=0.5)$ priors and specified that main effects had to be present for quadratic effects also to be included, resulting in a prior probability of 0.25 for quadratic effects. We specified the prior for the variance of observer random effects as half-Cauchy(1).

After selecting variables important for explaining each parameter, we analyzed the best-fit model, defined as the model containing only variables with higher posterior inclusion probabilities than prior inclusion probabilities, for each species. Priors for the best-fit models were selected to be vague and were similar to those used for variable selection. Differences include the exclusion of indicator variables and that we specified priors for coefficients as normal(mean $=$ $0, S D=2$ ) (Kruschke, 2015) rather than using hierarchical shrinkage priors because the set of covariates was reduced in the best-fit models. Parameter estimates presented in the "Results" section are based on these best-fit models.

To refine the survey protocol, we further used the output from the best-fit models to estimate the cumulative probability of detection of toads under different survey conditions. The survey conditions examined were based on variables supported for each population. We calculated the cumulative probability of detection $\left(\hat{p}^{*}\right)$ as $\hat{p}^{*}=1-(1-\hat{p})^{n}$, where $\hat{p}$ is the single-survey detection probability, and $n$ is the number of surveys conducted.

We used Bayesian analysis by MCMC methods for all models. We used Just Another Gibbs Sampler (JAGS) version 4.3.0 (Plummer, 2017) called from $R$ version 3.4.0 (R Core Team, 2017) using the package "runjags" (Denwood, 2016). We ran each model on five independent chains of 20,000 iterations each, after a burn-in of 10,000 iterations. We assessed convergence with the Gelman-Rubin statistic (Gelman and Rubin, 1992) and by examining history plots, and we ensured that all parameters had effective sample sizes $>1,000$. Unless otherwise noted, we report posterior summaries as medians and 95 percent credible intervals (0.025-0.975 quantile) from the best-fit models.

\section{Results}

\section{Dixie Valley Toads}

In total, we detected Dixie Valley toads in 38 (34 adult, 9 larvae, 5 both) of 60 plots across all surveys. This included 18 (13 adult, 6 larvae, 1 both) plots with detections in surveys conducted April 21-23, 2018 and 37 (34 adult, 6 larvae, 3 both) plots with detections in surveys conducted May 14-21, 2018. We made 142 total observations of adults and 1,522 observations of larvae on plots across all surveys.

Probability of occurrence of adult Dixie Valley toads was affected by survey period and water temperature (table 1). Based on the best-fit model, $\psi$ of adult toads in a plot with average water temperature $\left(18.8^{\circ} \mathrm{C}\right)$ in April was median $=0.77(95$ percent credible interval $=0.55-0.98)$, whereas $\psi$ of adult toads at the same water temperature in May was 10.1 (1.47-111) times higher (on the logit-scale) than in April, with median $\psi=0.91$ (0.60-0.99; fig. 6). Adult Dixie Valley toad $\psi$ was highest at cool, but not cold, water temperatures between 12 and $18^{\circ} \mathrm{C}\left(\beta_{\mathrm{tw}}=-1.27[-3.02-0.29]\right.$; $\beta_{\mathrm{tw}^{\wedge} 2}=-0.99$ [-2.50-0.38]; fig. 6). 
A.

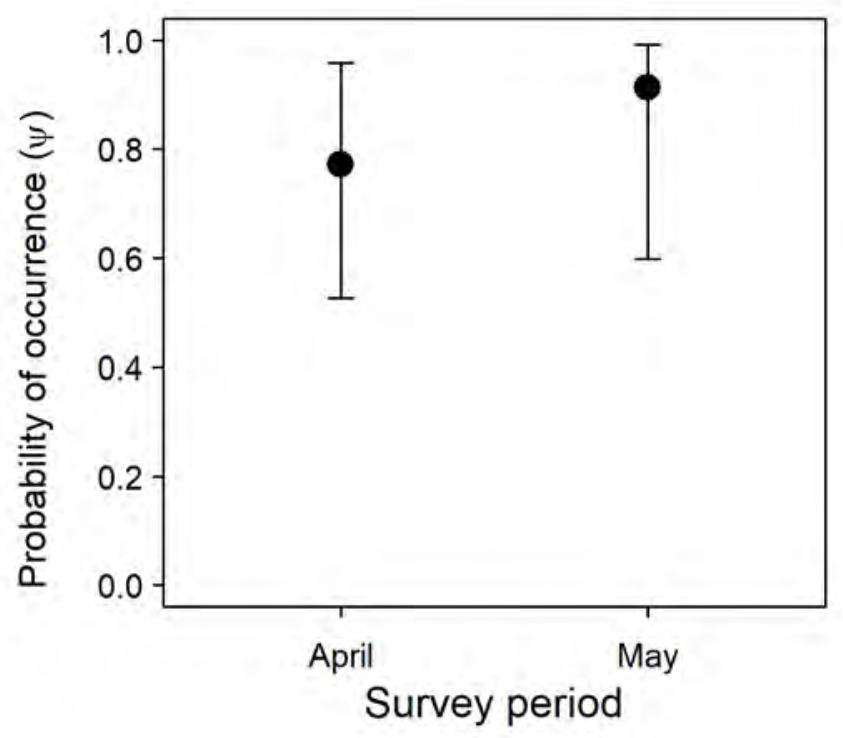

B.

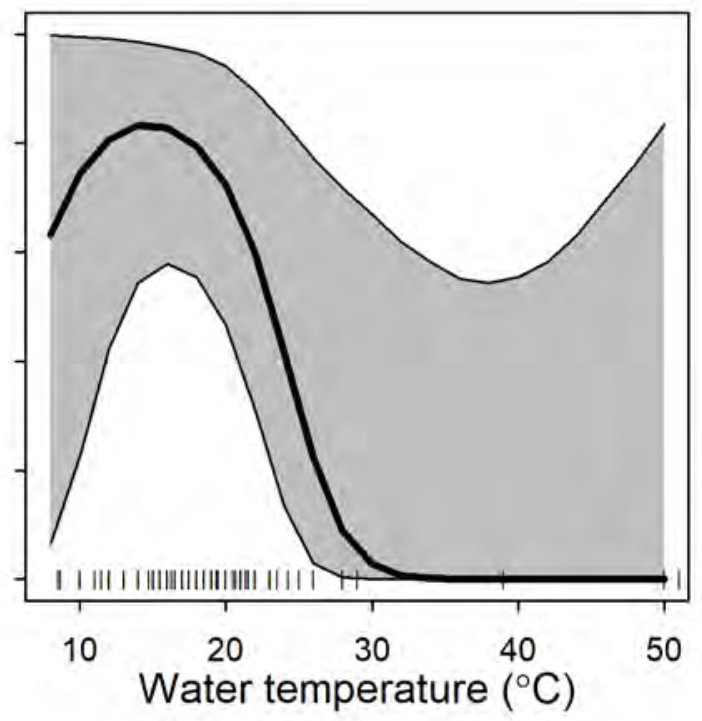

Figure 6. Probability of occurrence $(\psi)$ of adult Dixie Valley toads (Anaxyrus williamsi) in relation to $A$, survey period, and $B$, water temperature in the Dixie Valley, Churchill County, Nevada, 2018. In $A$, water temperature was held constant at its mean value of $18.8^{\circ} \mathrm{C}$, and in $B$, the plot represents $\psi$ in April. The points and bold line indicate posterior median $\psi$; error bars and the gray shaded area and thin lines indicate the 95 percent credible interval. Vertical lines along the abscissa indicate observed water temperatures.

The probability that Dixie Valley toads reproduced in a plot adults occupied was affected by the percent of the surface of the plot that was wet and water temperature (table 1). Based on the best-fit model, $r$ in an average plot (45 percent covered by water at $18.8^{\circ} \mathrm{C}$ ) was $0.10(0.01-0.26)$. The probability of reproduction in an occupied plot increased 8.88 (2.72-42.4) times with a 39 percent increase in wetted surface area (fig. 7). The model indicated that Dixie Valley toad $r$ was highest at warm to hot water temperatures between 26 and $42^{\circ} \mathrm{C}$ $\left(\gamma_{\mathrm{tw}}=3.34\right.$ [1.29-5.57]; $\gamma_{\mathrm{tw}^{\wedge} 2}=-0.71$ [-3.49-2.10]; fig. 7), but only three observed water temperatures were $>29^{\circ} \mathrm{C}$. The proportion of plots in April occupied by adult Dixie Valley toads but not used for reproduction was $0.68(0.44-0.89)$, the proportion of plots used for reproduction was $0.08(0.02-$ 0.23 ), and the proportion of sites not used by toads was 0.23 (0.04-0.47). Corresponding values for May were 0.80 (0.51$0.94), 0.09(0.02-0.27)$, and $0.09(0.01-0.40)$, respectively.

Detection probabilities for adult Dixie Valley toads $\left(p_{2}\right)$ were affected by survey period, survey duration, and percent cover of emergent vegetation (table 2). Based on the bestfit model, $p_{2}$ for adult toads in a plot with average cover of emergent vegetation ( 66.5 percent) surveyed for 8.5 minutes in April was 0.17 (0.02-0.46), whereas $p_{2}$ for adult toads under the same conditions in May was 3.31 (0.91-11.0) times higher (on the logit-scale) than in April, with median $p_{2}=0.40(0.15-0.79$; fig. 8$)$. For every 3 -minute increase in survey duration, $p_{2}$ increased 8.70 (4.07-21.1) times (fig. 8). Emergent vegetation also had a positive effect on $p_{2}$; for every 32 percent increase in emergent vegetation cover, $p_{2}$ increased 1.90 (1.05-3.61) times (fig. 8).

Detection probabilities for larval Dixie Valley toads $\left(p_{3}\right)$ were affected by survey duration, time of day, and percent cover of emergent vegetation (table 2). Based on the bestfit model, $p_{3}$ for larval toads in a plot with average cover of emergent vegetation (66.5 percent) surveyed for 8.5 minutes during the day was $0.38(0.08-0.76)$, whereas $p_{3}$ for larval toads under the same conditions but surveyed at night was $0.03(<0.01-0.81)$ times as high as during the day, with median nocturnal $p_{3}=0.03(<0.01-0.43$; fig. 9). For every 3 -minute increase in survey duration, $p_{3}$ increased 38.2 (7.04367) times (fig. 9). Emergent vegetation had a negative effect on $p_{3}$; for every 32 percent increase in emergent vegetation cover, $p_{3}$ was 0.29 (0.08-0.93) times as high (fig. 9). 
Table 1. Posterior inclusion probabilities for variables affecting probability of occurrence of adults $(\psi)$ and probability of reproduction (r) of Dixie Valley toads (Anaxyrus williamsi) in the Dixie Valley, Churchill County, Nevada, 2018.

[Posterior probabilities for linear effects of variables that also include quadratic effects are for the linear effect only. All models with quadratic effects also included linear effects of the same variable. Values in bold indicate higher posterior inclusion probabilities than prior inclusion probabilities; these variables for each parameter were included in the best-fit model]

\begin{tabular}{lccccccc}
\hline & \multicolumn{3}{c}{ Variable } \\
\cline { 2 - 8 } Parameter & $\begin{array}{c}\text { Survey } \\
\text { period }\end{array}$ & $\begin{array}{c}\text { Percent } \\
\text { emergent } \\
\text { vegetation }\end{array}$ & $\begin{array}{c}\text { Percent } \\
\text { emergent } \\
\text { vegetation } \\
\text { squared }\end{array}$ & $\begin{array}{c}\text { Percent } \\
\text { wetted surface }\end{array}$ & $\begin{array}{c}\text { Mean } \\
\text { water depth }\end{array}$ & $\begin{array}{c}\text { Water } \\
\text { temperature }\end{array}$ & $\begin{array}{c}\text { Water } \\
\text { temperature } \\
\text { squared }\end{array}$ \\
\hline$\psi$ & $\mathbf{0 . 9 5 7}$ & 0.338 & 0.153 & 0.410 & 0.412 & 0.346 & $\mathbf{0 . 3 8 6}$ \\
$r$ & 0.301 & 0.154 & 0.076 & $\mathbf{0 . 9 9 6}$ & 0.238 & 0.497 & $\mathbf{0 . 4 9 5}$ \\
\hline
\end{tabular}

A.

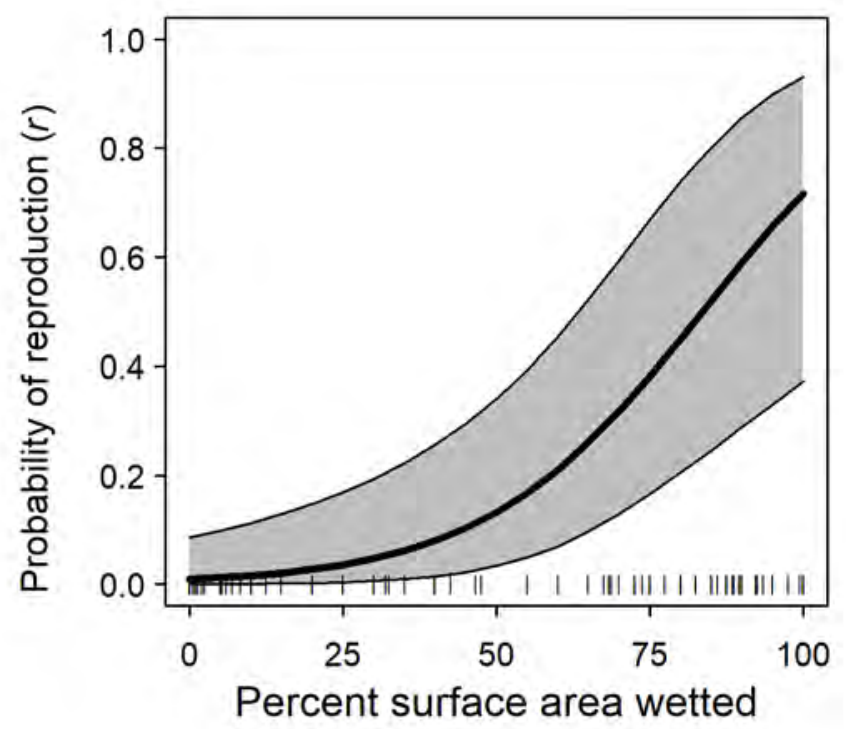

B.

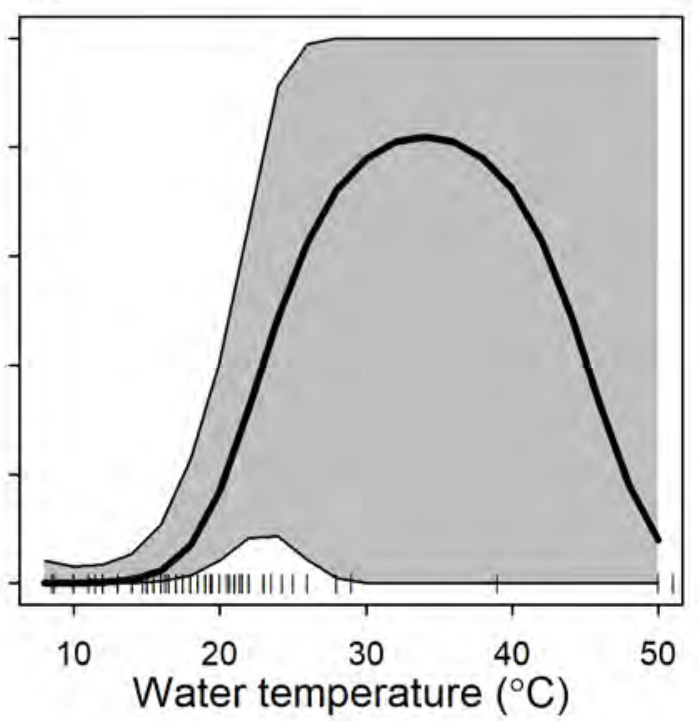

Figure 7. Probability of reproduction ( $r$ ) of Dixie Valley toads (Anaxyrus williamsi) in occupied plots in relation to $A$, percent of plot surface covered by water, and $B$, water temperature in the Dixie Valley, Churchill County, Nevada, 2018. Each plot holds the value of the other predictor variable constant at its mean value. The bold lines indicate posterior median $r$, the gray shaded areas and thin lines indicate 95 percent credible intervals. Vertical lines along the abscissa indicate observed values.

Table 2. Posterior inclusion probabilities for variables affecting detection probability of adult $\left(p_{2}\right)$ and larval $\left(p_{3}\right)$ Dixie Valley toads (Anaxyrus williamsi) in the Dixie Valley, Churchill County, Nevada, 2018.

[Values in bold indicate higher posterior inclusion probabilities than prior inclusion probabilities; these variables for each parameter were included in the best-fit model]

\begin{tabular}{lccccc}
\hline & \multicolumn{5}{c}{ Variable } \\
\cline { 2 - 6 } Parameter & $\begin{array}{c}\text { Survey } \\
\text { period }\end{array}$ & $\begin{array}{c}\text { Survey } \\
\text { duration }\end{array}$ & $\begin{array}{c}\text { Air } \\
\text { temperature }\end{array}$ & $\begin{array}{c}\text { Time } \\
\text { of day }\end{array}$ & $\begin{array}{c}\text { Percent } \\
\text { emergent } \\
\text { vegetation }\end{array}$ \\
\hline$p_{2}$ & $\mathbf{0 . 6 1 3}$ & $>\mathbf{0 . 9 9 9}$ & 0.187 & 0.264 & $\mathbf{0 . 6 4 6}$ \\
$p_{3}$ & 0.362 & $>\mathbf{0 . 9 9 9}$ & 0.212 & $\mathbf{0 . 9 5 8}$ & $\mathbf{0 . 8 9 0}$ \\
\hline
\end{tabular}


A.

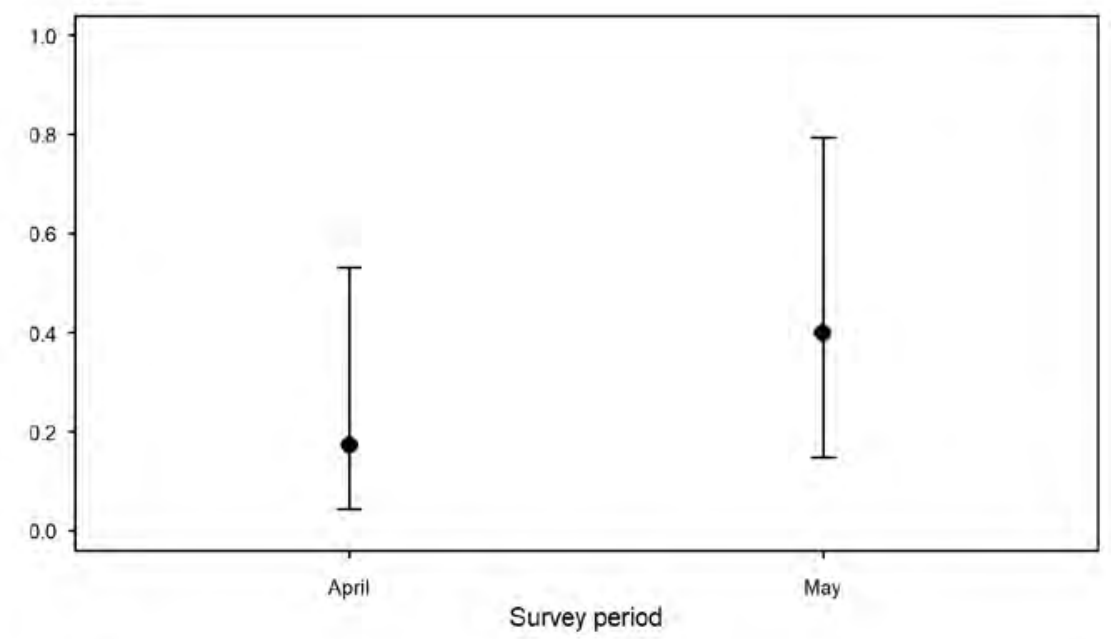

B.

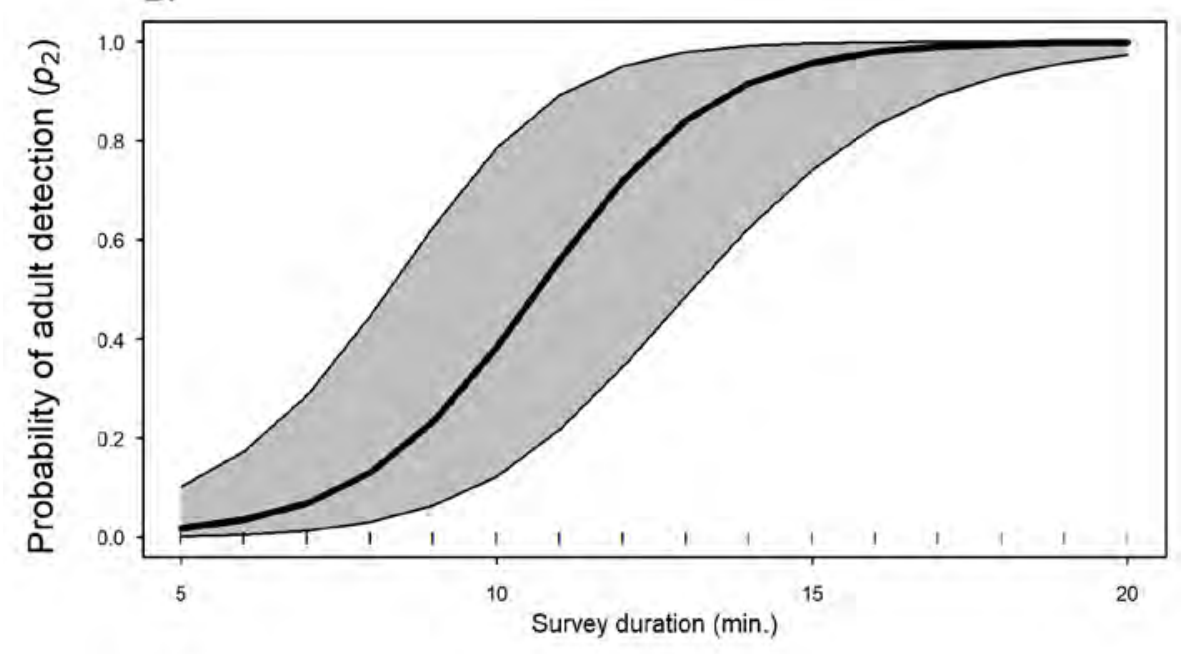

C.

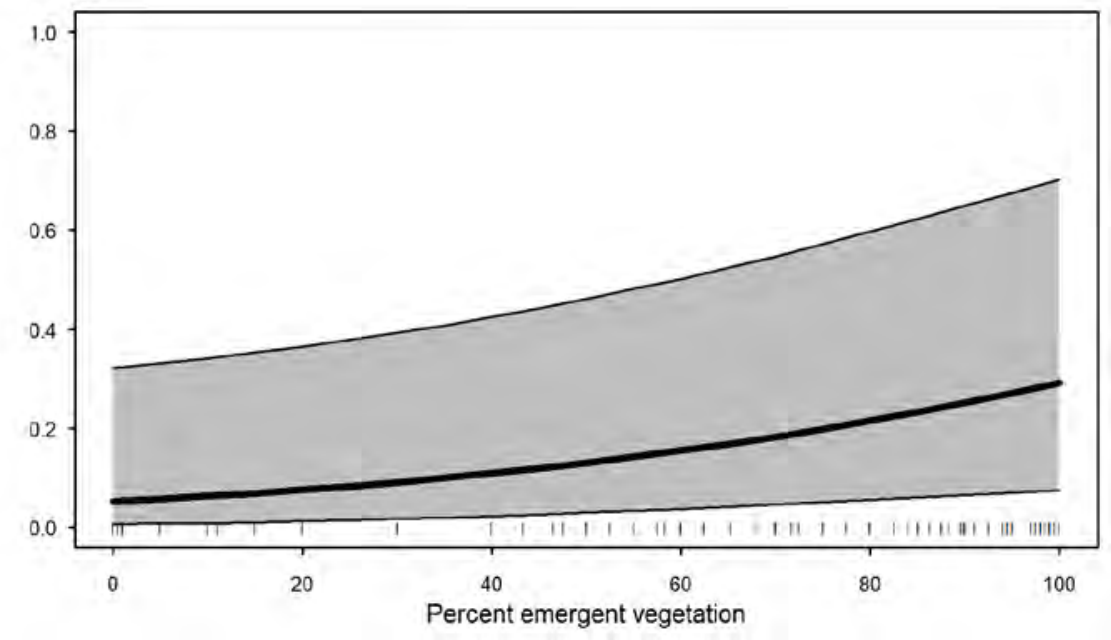

Figure 8. Detection probability of adult $\left(p_{2}\right)$ Dixie Valley toads (Anaxyrus williamsi) in relation to $A$, survey period; $B$, survey duration; and $C$, percent emergent vegetation in the Dixie Valley, Churchill County, Nevada, 2018. Plots for each variable hold the other variables constant at their mean values; for $B$ and $C$, plots represent surveys conducted in April. Points and bold lines indicate posterior median $p_{2}$; error bars and gray shaded areas indicate 95 percent credible intervals. Vertical lines along the abscissa indicate observed values. 
A.

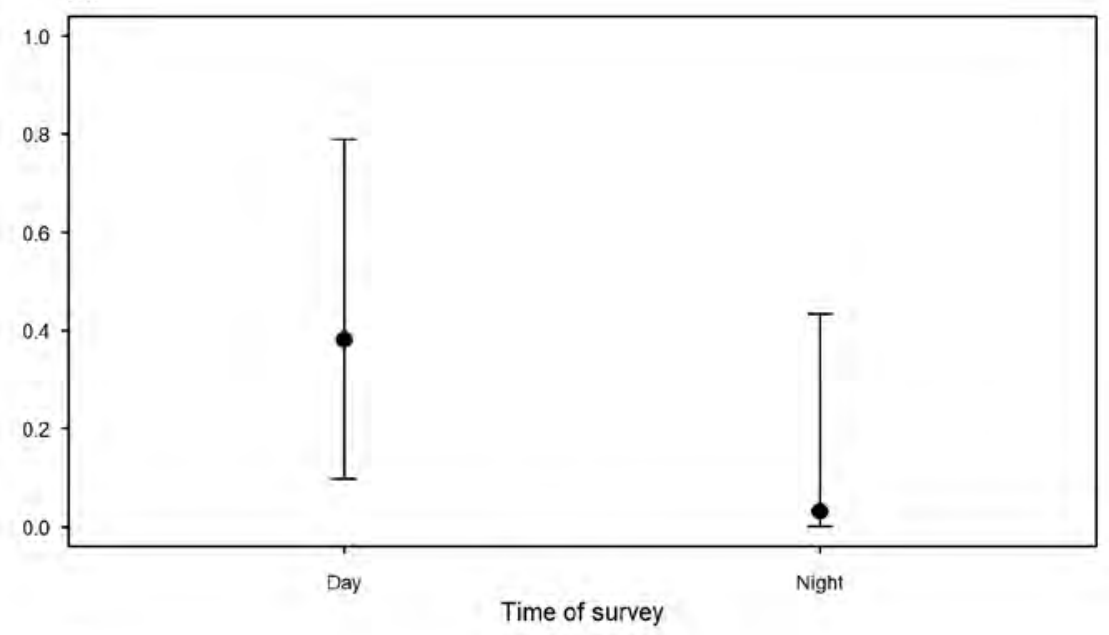

B.

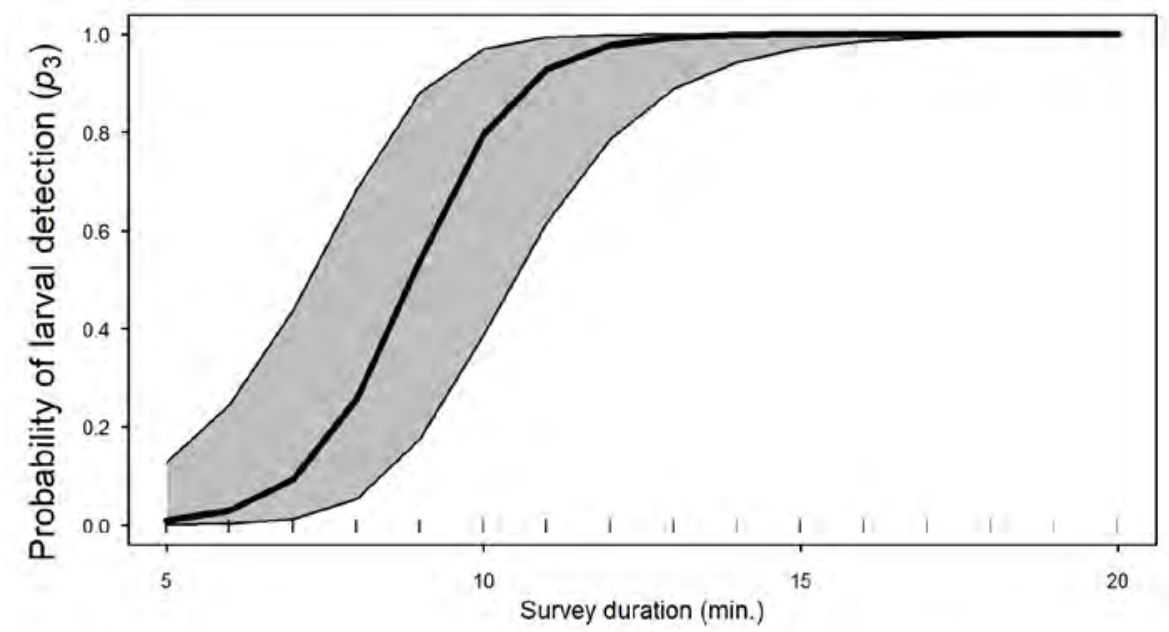

C.

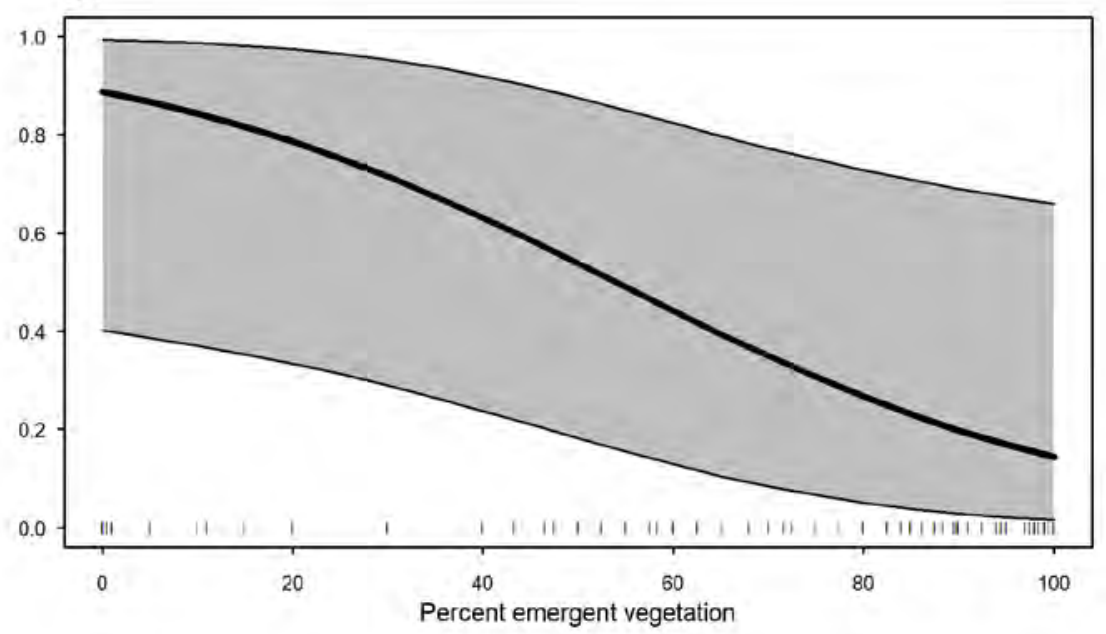

Figure 9. Detection probability of larval $\left(p_{3}\right)$ Dixie Valley toads (Anaxyrus williamsi) in relation to $A$, time of survey; $B$, survey duration; and $C$, percent emergent vegetation in the Dixie Valley, Churchill County, Nevada, 2018. Plots for each variable hold the other variables constant at their mean values; for $B$ and $C$, plots represent surveys conducted during the day. Points and bold lines indicate posterior median $p_{3^{\prime}}$ error bars and gray shaded areas indicate 95 percent credible intervals. Vertical lines along the abscissa indicate observed values. 


\section{Toads in the Railroad Valley}

In total, we detected western toads in the Railroad Valley (hereafter, Railroad Valley toads) in 5 (4 adult, 1 larvae, 0 both) of 60 plots across all surveys. We made 10 observations of adults and 37 observations of larvae, the latter within a single survey.

Probability of occurrence of adult Railroad Valley toads was unaffected by percent wetted surface area of the plot (posterior inclusion probability $=0.430$ ). Based on the best-fit model, $\psi$ of adult Railroad Valley toads was 0.44 (0.12-0.92). Although the posterior inclusion probability for the effect of percent wetted surface area of the plot on $r$ was 0.503 , we did not include predictor variables for $r$ in the best-fit model because we had only one observation of pre-metamorphic life stages. The probability an occupied plot would be used for reproduction by Railroad Valley toads was $0.26(<0.01-0.84)$. The proportion of plots occupied by Railroad Valley toads but not used for reproduction was $0.28(0.03-0.81)$, the proportion of plots used for reproduction was $0.10(0.01-0.54)$, and the proportion of sites not used by toads was $0.56(0.06-0.86)$.

Detection probabilities for adult Railroad Valley toads $\left(p_{2}\right)$ were affected by survey duration (table 3 ). Based on the best-fit model, for every 2.8-minute increase in survey duration, $p_{2}$ increased 4.25 (1.62-24.4) times (fig. 10). Larval detection probability $\left(p_{3}\right)$ was affected by survey duration and time of day (table 3 ). Based on the best-fit model, $p_{3}$ for a survey conducted for 7.4 minutes during the day was 0.09 $(<0.01-0.59)$, whereas $p_{3}$ for larval toads under the same conditions but surveyed at night was $0.24(0.01-5.24)$ times as high as during the day, with median nocturnal $p_{3}=0.02$ $(<0.01-0.55$; fig. 11). For every 2.8-minute increase in survey duration, $p_{3}$ increased 3.62 (0.82-48.0) times (fig. 11).

Table 3. Posterior inclusion probabilities for variables affecting detection probability of adult $\left(p_{2}\right)$ and larval $\left(p_{3}\right)$ western toads (Anaxyrus boreas ssp.) in the Railroad Valley, Nye County, Nevada, 2018.

[Values in bold indicate higher posterior inclusion probabilities than prior inclusion probabilities; these variables for each parameter were included in the best-fit model]

\begin{tabular}{lccc}
\hline \multirow{2}{*}{ Parameter } & \multicolumn{3}{c}{ Variable } \\
\cline { 2 - 4 } & $\begin{array}{c}\text { Survey } \\
\text { duration }\end{array}$ & $\begin{array}{c}\text { Air } \\
\text { temperature }\end{array}$ & $\begin{array}{c}\text { Time } \\
\text { of day }\end{array}$ \\
\hline$p_{2}$ & $\mathbf{0 . 8 6 8}$ & 0.449 & 0.397 \\
$p_{3}$ & $\mathbf{0 . 5 5 6}$ & 0.432 & $\mathbf{0 . 5 5 8}$ \\
\hline
\end{tabular}

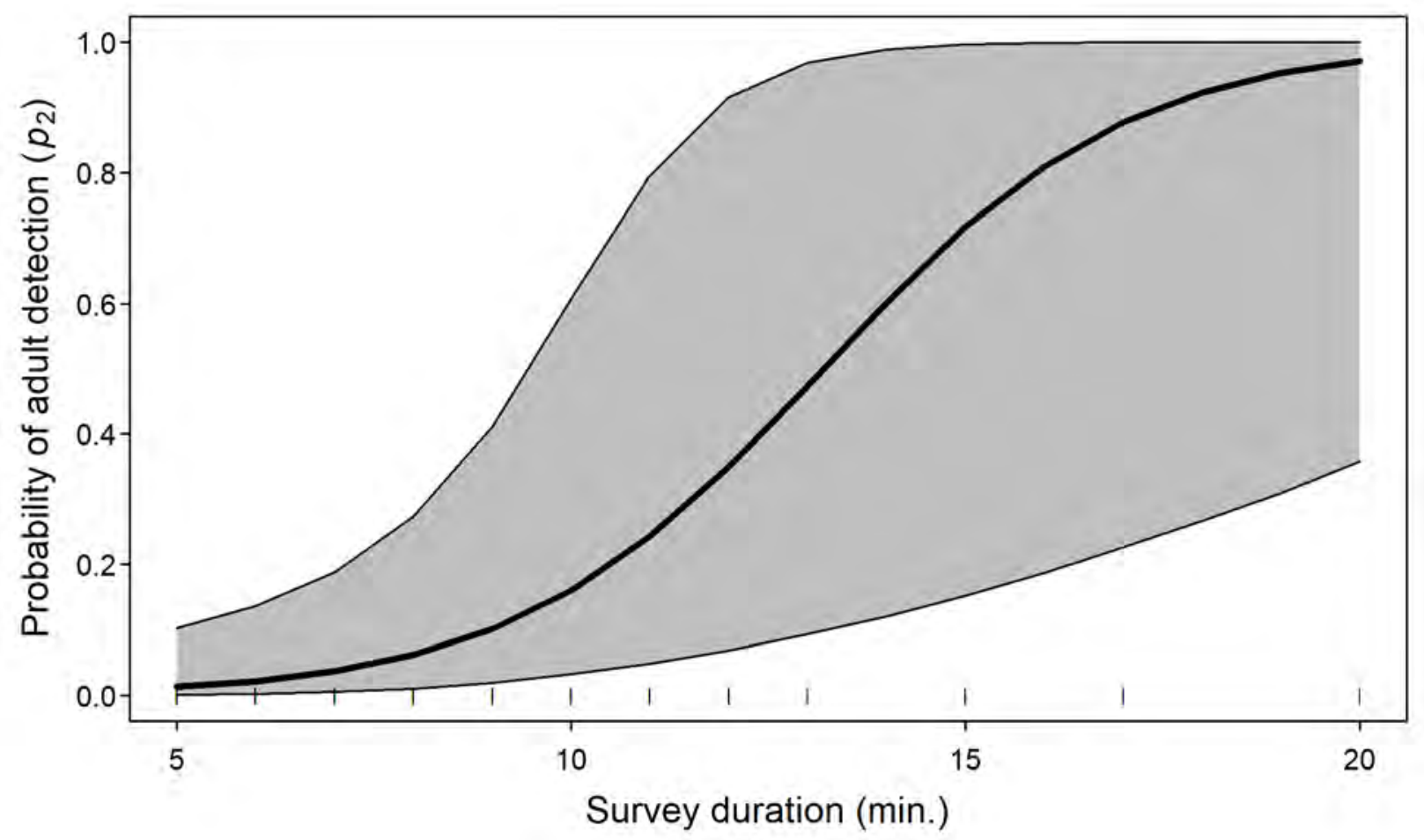

Figure 10. Detection probability of adult $\left(p_{2}\right)$ western toads (Anaxyrus boreas ssp.) in the Railroad Valley, Nye County, Nevada, 2018, in relation to survey duration. The bold line indicates posterior median $p_{2^{\prime}}$ the gray shaded area indicates the 95 percent credible interval. Vertical lines along the abscissa indicate observed values. 


\section{Toads at Hot Creek}

In total, we detected western toads at Hot Creek (hereafter, Hot Creek toads) in 17 (16 adult, 2 larvae, 1 both) of 51 plots across all surveys. We made 49 observations of adults and 103 observations of larvae. Probability of occurrence of adult Hot Creek toads was unaffected by any of the variables we evaluated (table 4). Based on the bestfit model, $\psi$ of adult Hot Creek toads was 0.59 (0.34-0.90). The probability that Hot Creek toads reproduced in a plot they occupied was affected by the percent of the surface of the plot that was wet and percent cover of emergent vegetation (table 4). Based on the best-fit model, $r$ in an average plot ( 56 percent covered by water with 76 percent emergent vegetation) was $0.29(0.02-0.70)$. The probability of reproduction in an occupied plot increased 7.15 (0.65173 ) times with a 31 percent increase in wetted surface area (fig. 12). The model indicated that Hot Creek toad $r$ was highest between 65 percent and 90 percent emergent vegetation cover $\left(\gamma_{\mathrm{em}}=0.19[-3.22-3.99] ; \gamma_{\mathrm{em}^{\prime 2}}=-1.80\right.$ [-4.95-1.08]; fig. 12). The proportion of plots occupied by Hot Creek toads but not used for reproduction was 0.40 (0.11-0.78), the proportion of plots used for reproduction was $0.17(0.03-0.46)$, and the proportion of sites not occupied by toads was $0.41(0.08-0.65)$.

Detection probabilities for adult Hot Creek toads $\left(p_{2}\right)$ were affected by survey duration and time of day (table 5). Based on the best-fit model, $p_{2}$ for a 9.1-minute diurnal survey (mean survey duration) was $0.09(0.02-0.20)$, whereas $p_{2}$ for a nocturnal survey of the same duration was $5.31(1.59-22.1)$ times higher than during the day, with nocturnal $p_{2}=0.33$ (0.11-0.72; fig. 13). For every 2.7-minute (1 SD) increase in survey duration, $p_{2}$ increased 4.10 (2.03-9.90) times (fig. 13).
A.

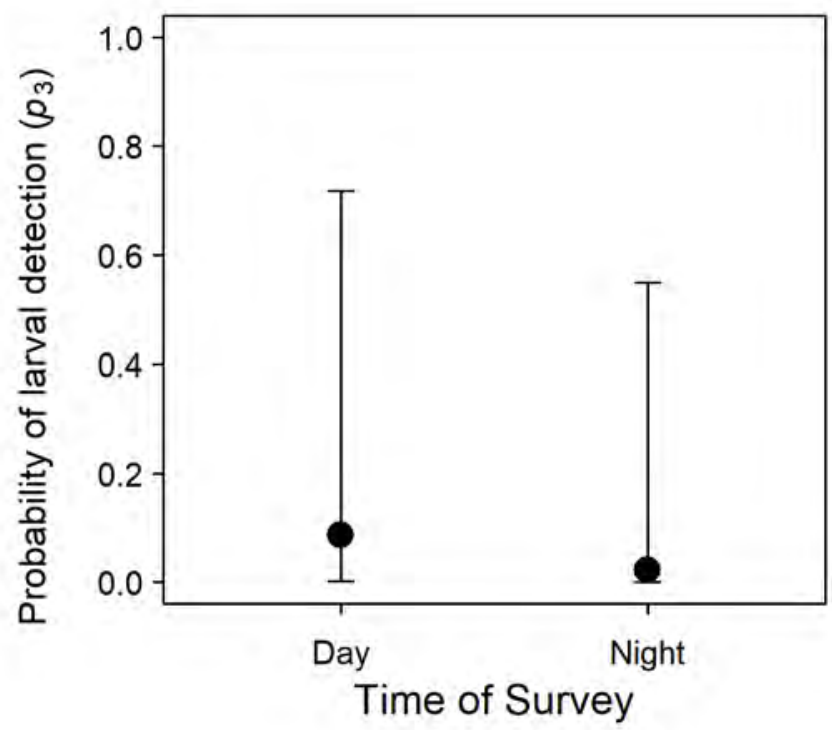

B.

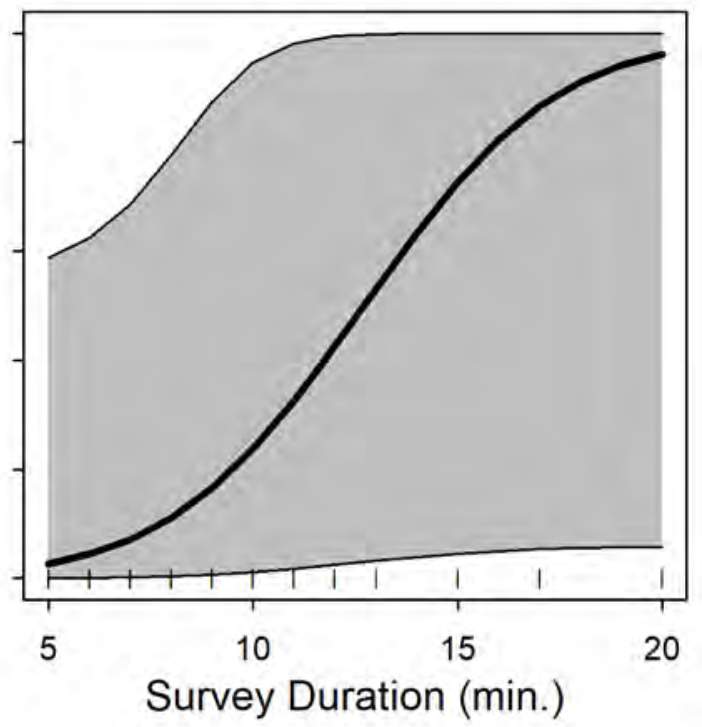

Figure 11. Detection probability of larval $\left(p_{3}\right)$ western toads (Anaxyrus boreas ssp.) in the Railroad Valley, Nye County, Nevada, 2018, in relation to $A$, time of survey, and $B$, survey duration. $A$ holds survey duration constant at its mean value (7.4 minutes), and $B$ represents surveys conducted during the day. Points and bold lines indicate posterior median $p_{3^{\prime}}$ error bars and gray shaded areas indicate 95 percent credible intervals. Vertical lines along the abscissa indicate observed values.

Table 4. Posterior inclusion probabilities for variables affecting probability of adult occurrence $(\psi)$ and probability of reproduction ( $r)$ of western toads (Anaxyrus boreas ssp.) at Hot Creek, Nye County, Nevada, 2018.

[Posterior probabilities for linear effects of variables that also include quadratic effects are for the linear effect only. All models with quadratic effects also included linear effects of the same variable. Values in bold indicate higher posterior inclusion probabilities than prior inclusion probabilities; these variables for each parameter were included in the best-fit model]

\begin{tabular}{lcccccc}
\hline \multirow{2}{*}{ Parameter } & \multicolumn{4}{c}{ Variable } \\
\cline { 2 - 7 } & $\begin{array}{c}\text { Percent emergent } \\
\text { vegetation }\end{array}$ & $\begin{array}{c}\text { Percent emergent } \\
\text { vegetation squared }\end{array}$ & $\begin{array}{c}\text { Percent } \\
\text { wetted surface }\end{array}$ & $\begin{array}{c}\text { Mean } \\
\text { water depth }\end{array}$ & $\begin{array}{c}\text { Water } \\
\text { temperature }\end{array}$ & $\begin{array}{c}\text { Water temperature } \\
\text { squared }\end{array}$ \\
\hline$\psi$ & 0.210 & 0.167 & 0.390 & 0.490 & 0.276 & 0.197 \\
$r$ & 0.295 & $\mathbf{0 . 3 7 7}$ & $\mathbf{0 . 7 2 4}$ & 0.388 & 0.293 & 0.201 \\
\hline
\end{tabular}


A.

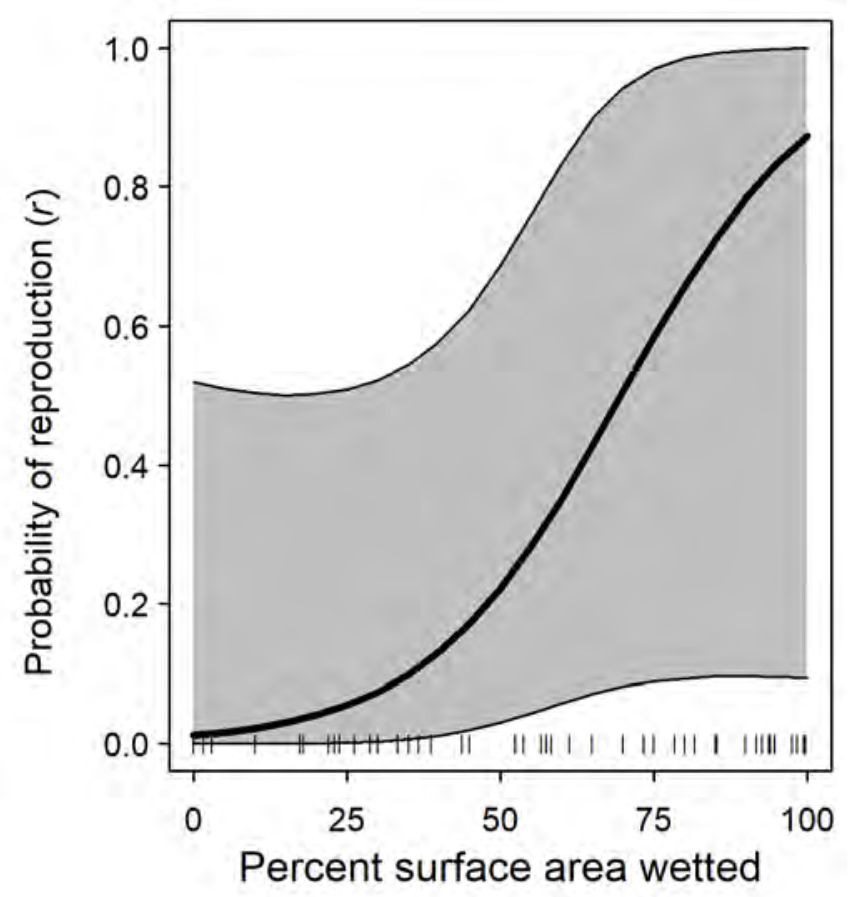

B.

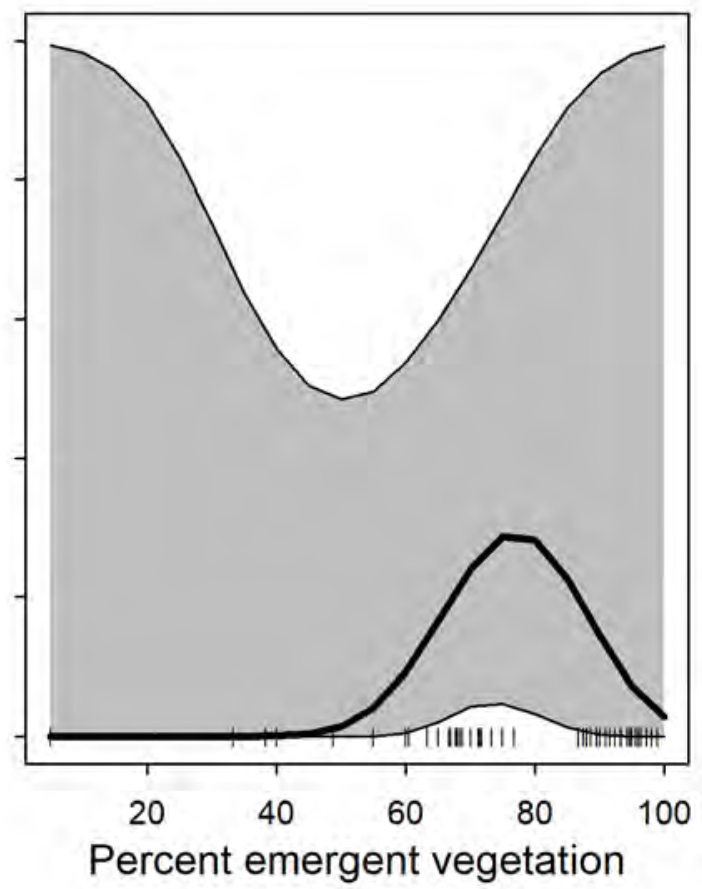

Figure 12. Probability of reproduction ( $r$ ) of western toads (Anaxyrus boreas ssp.) at Hot Creek, Nye County, Nevada, 2018, in occupied plots in relation to $A$, percent of plot surface covered by water, and $B$, percent emergent vegetation. Each plot holds the value of the other predictor variable constant at its mean value. The bold lines indicate posterior median $r$, the gray shaded areas and thin lines indicate 95 percent credible intervals. Vertical lines along the abscissa indicate observed values.

Table 5. Posterior inclusion probabilities for variables affecting detection probability of adult $\left(p_{2}\right)$ and larval $\left(p_{3}\right)$ western toads (Anaxyrus boreas ssp.) at Hot Creek, Nye County, Nevada, 2018.

[Values in bold indicate higher posterior inclusion probabilities than prior inclusion probabilities; these variables for each parameter were included in the best-fit model]

\begin{tabular}{lcccc}
\hline & \multicolumn{4}{c}{ Variable } \\
\cline { 2 - 5 } Parameter & $\begin{array}{c}\text { Survey } \\
\text { duration }\end{array}$ & $\begin{array}{c}\text { Air } \\
\text { temperature }\end{array}$ & Time of day & $\begin{array}{c}\text { Percent } \\
\text { emergent } \\
\text { vegetation }\end{array}$ \\
\hline$p_{2}$ & $\mathbf{0 . 9 9 7}$ & 0.281 & $\mathbf{0 . 8 5 9}$ & 0.364 \\
$p_{3}$ & 0.290 & 0.308 & 0.387 & $\mathbf{0 . 9 1 4}$ \\
\hline
\end{tabular}

Detection probabilities for larval Hot Creek toads $\left(p_{3}\right)$ were affected by percent cover of emergent vegetation (table 5). Based on the best-fit model, $p_{3}$ for toads in a plot with average cover of emergent vegetation (76 percent) was 0.33 (0.06-0.68). Emergent vegetation had a negative effect on $p_{3}$; for every 20 percent increase in emergent vegetation cover, $p_{3}$ was $0.04(<0.01-2.21)$ times as high (fig. 14). 
A.

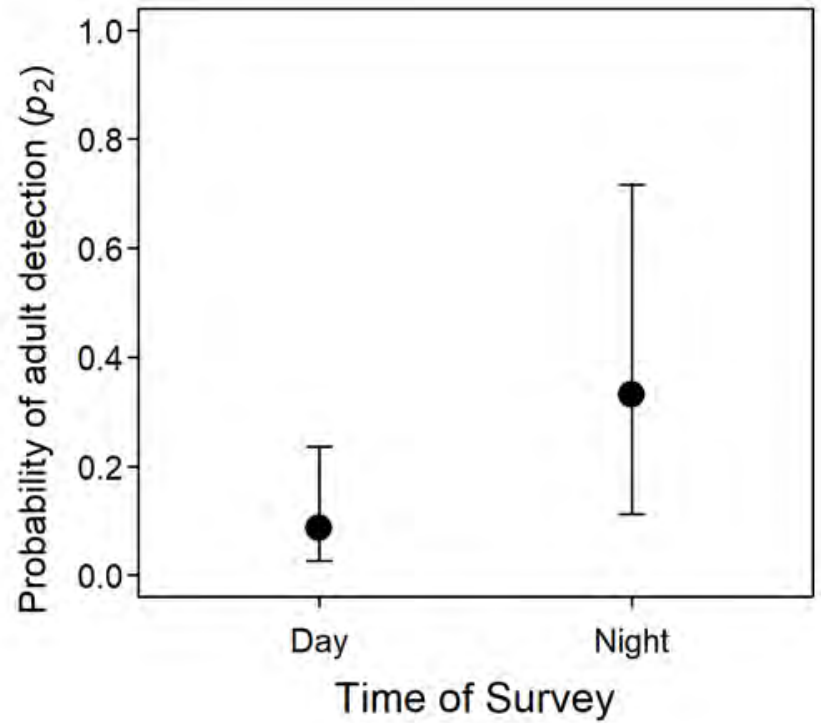

B.

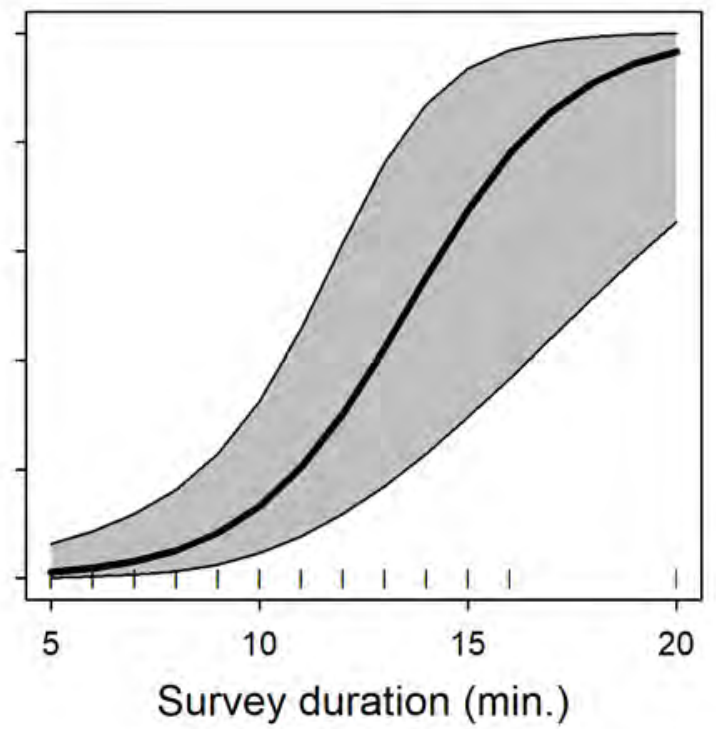

Figure 13. Detection probability of adult $\left(p_{2}\right)$ western toads (Anaxyrus boreas ssp.) at Hot Creek, Nye County, Nevada, 2018, in relation to $A$, time of survey, and $B$, survey duration. $A$ holds survey duration constant at its mean value (9.1 minute), and $B$ represents surveys conducted during the day. Points and bold lines indicate posterior median $p_{3^{\prime}}$ error bars and gray shaded areas indicate 95 percent credible intervals. Vertical lines along the abscissa indicate observed values.

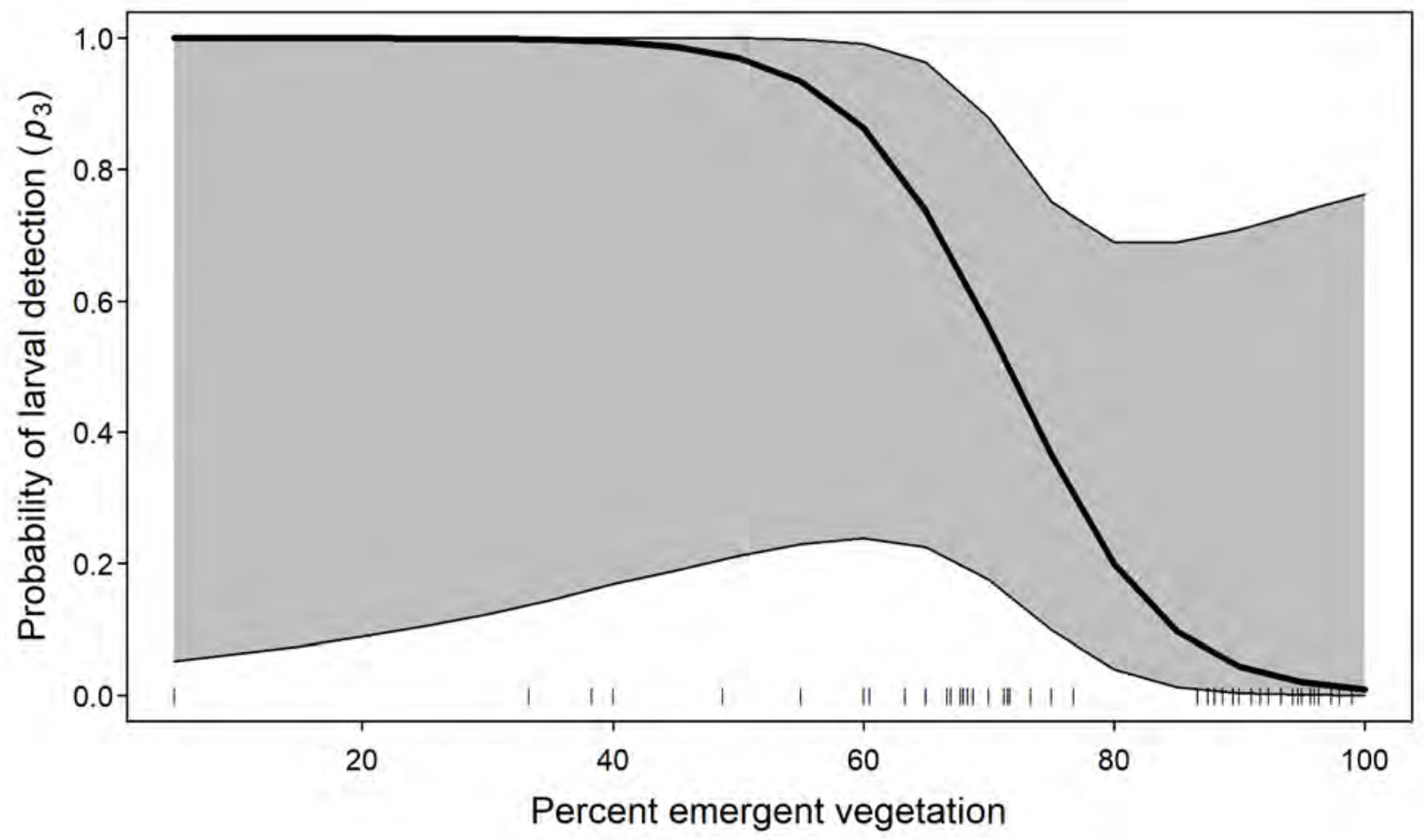

Figure 14. Detection probability of larval ( $\left.p_{3}\right)$ western toads (Anaxyrus boreas ssp.) at Hot Creek, Nye County, Nevada, 2018, in relation to percent emergent vegetation. The bold line indicates posterior median $p_{3^{3}}$ the gray shaded area indicates the 95 percent credible interval. Vertical lines along the abscissa indicate observed values. 


\section{Effects of Survey Conditions on Cumulative Detection Probabilities}

For adult Dixie Valley toads, survey period and survey duration were important predictors of $p_{2}$. In both months, cumulative detection probability $\left(p_{2}{ }^{*}\right)$ increased more quickly with increasing survey duration than increasing number of surveys (fig. 15). Median $p_{2}{ }^{*}$ was high with low uncertainty with two surveys of 15 minutes or longer or three surveys of 12 minutes or longer in April (fig. 15); in May, the same $p_{2}{ }^{*}$ could be achieved with surveys of slightly shorter duration.

For larval Dixie Valley toads, both survey duration and time of day were important predictors of $p_{3}$. Diurnal surveys were more effective than nocturnal surveys, and this difference was larger than the effect of increasing number or duration of surveys (fig. 16). Two diurnal surveys of 10 minutes each resulted in median $p_{3} *$ that was high and precise, but surveys would have to be about 15 minutes to achieve the same $p_{3}{ }^{*}$ at night (fig. 16).

For adult Railroad Valley toads, survey duration was an important predictor of $p_{2}$. Cumulative detection probability $\left(p_{2}{ }^{*}\right)$ increased more quickly with increasing survey duration than increasing number of surveys (fig. 17). Median $p_{2}{ }^{*}$ was high with low uncertainty with two surveys of 20 minutes or longer or three surveys of 17 minutes or longer (fig. 17).
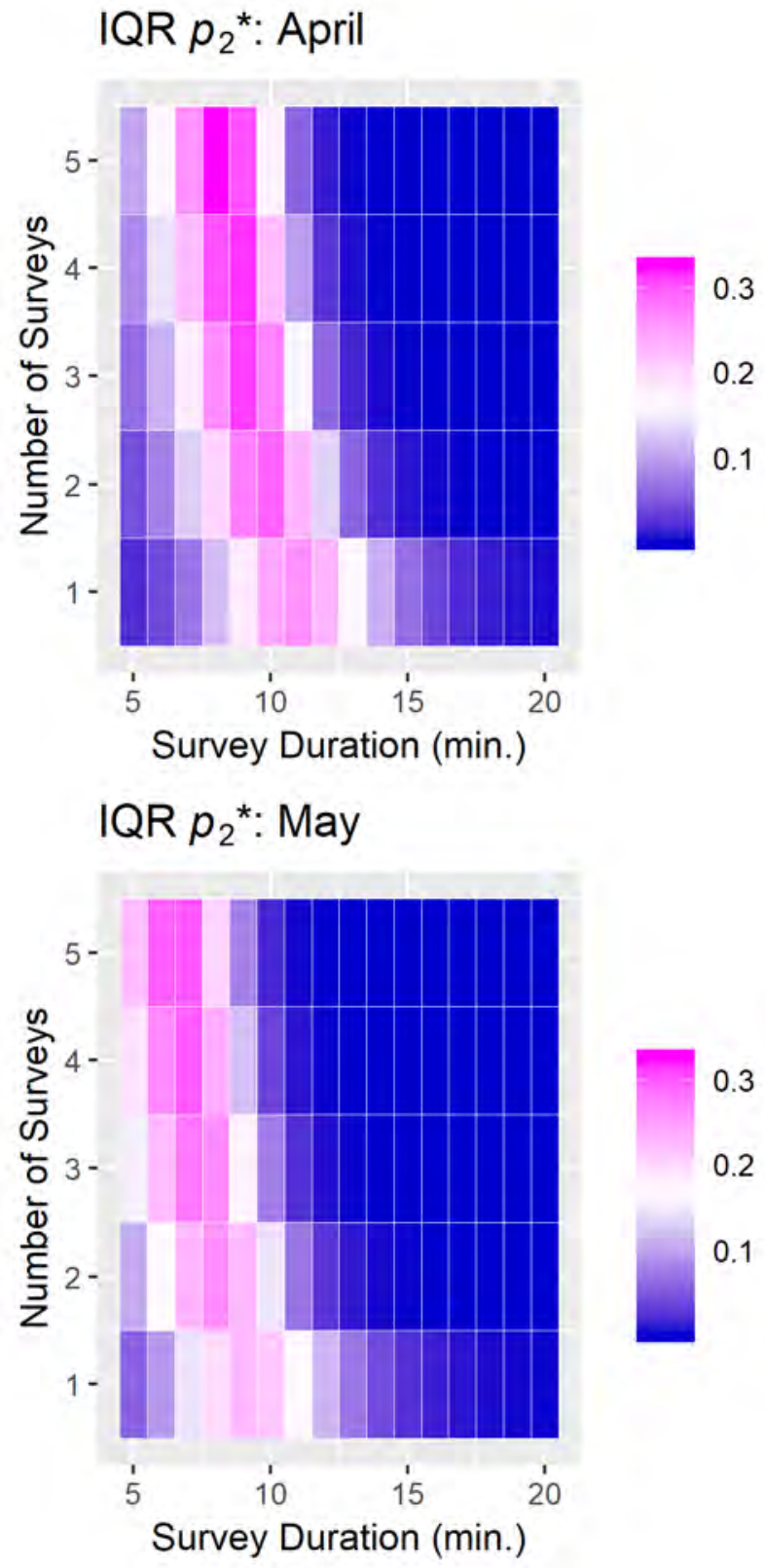

Figure 15. Cumulative detection probabilities of adult $\left(p_{2}^{*}\right)$ Dixie Valley toads (Anaxyrus williamsi) based on survey month, survey duration, and number of independent surveys. IQR = interquartile range. 



Figure 16. Cumulative detection probabilities of larval $\left(p_{3}^{*}\right)$ Dixie Valley toads (Anaxyrus williamsi) based on survey month, survey duration, and number of independent surveys. IQR = interquartile range. 

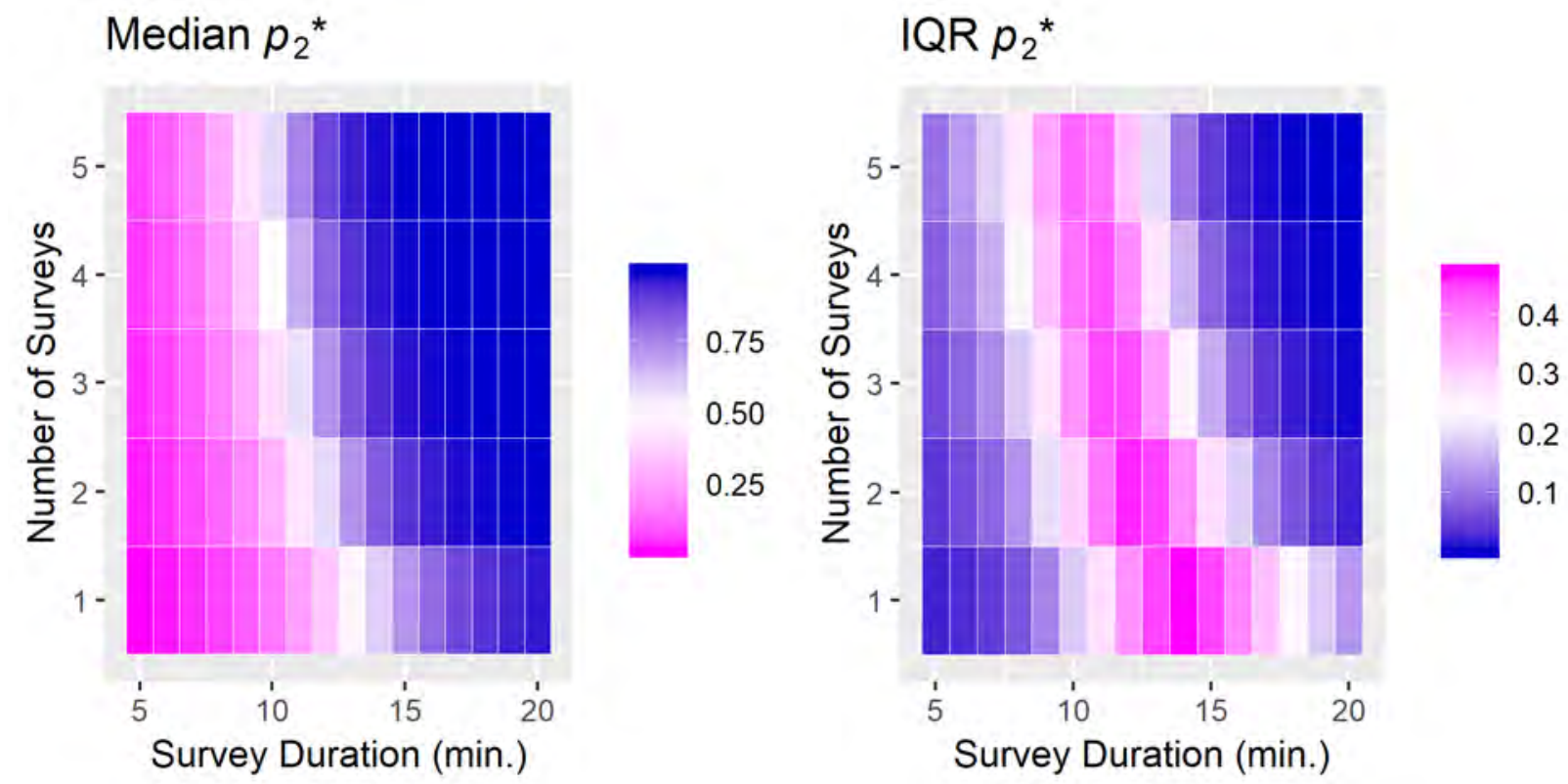

Figure 17. Cumulative detection probabilities of adult $\left(p_{2}{ }^{*}\right)$ western toads (Anaxyrus boreas ssp.) in the Railroad Valley, Nevada, based on survey duration and number of independent surveys. $I O R=$ interquartile range.

For larval Railroad Valley toads, both survey duration and time of day were important predictors of $p_{3}$. Diurnal surveys were more effective than nocturnal surveys, and this difference was larger than the effect of increasing number or duration of surveys (fig. 18). Two diurnal surveys of 20 minutes each resulted in median $p_{3}{ }^{*}$ that was high and precise, but five surveys of 20 minutes each would be required to achieve the same $p_{3}{ }^{*}$ at night (fig. 18).

For adult Hot Creek toads, survey duration and time of day were important predictors of $p_{2}$. Cumulative detection probability $\left(p_{2}^{*}\right)$ increased more quickly with increasing survey duration than increasing number of surveys, but the difference between diurnal and nocturnal surveys had greater influence on $p_{2}{ }^{*}$ (fig. 19). Median $p_{2}{ }^{*}$ was high with low uncertainty with two nocturnal surveys of 15 minutes or longer or three nocturnal surveys of 12 minutes or longer (fig. 19). Two surveys of 18 minutes or longer or three surveys of 16 minutes or longer would be required to achieve the same $p_{2}{ }^{*}$ during the day (fig. 19).

For larval Hot Creek toads emergent vegetation was an important predictor of $p_{3}$, whereas survey duration was not. Two surveys resulted in high and precise $p_{3}{ }^{*}$ at $<50$ percent emergent vegetation cover, but even five surveys were too few to achieve the same $p_{3}{ }^{*}$ at sites $>70$ percent emergent vegetation (fig. 20). 

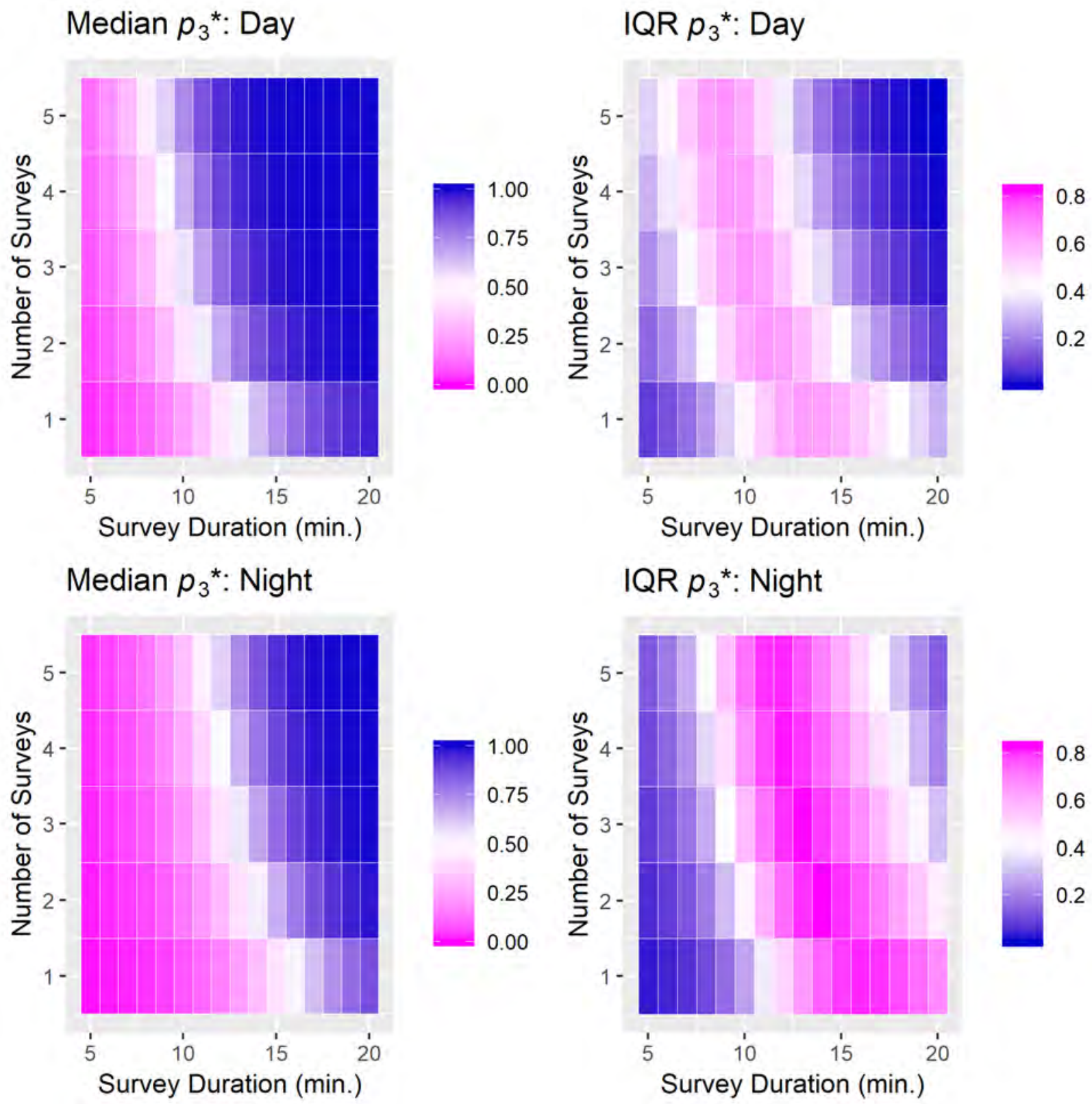

Figure 18. Cumulative detection probabilities of larval $\left(p_{3}^{*}\right)$ western toads (Anaxyrus boreas $s s p$.) in the Railroad Valley, Nevada, based on survey duration and number of independent surveys. $I Q R=$ interquartile range. 

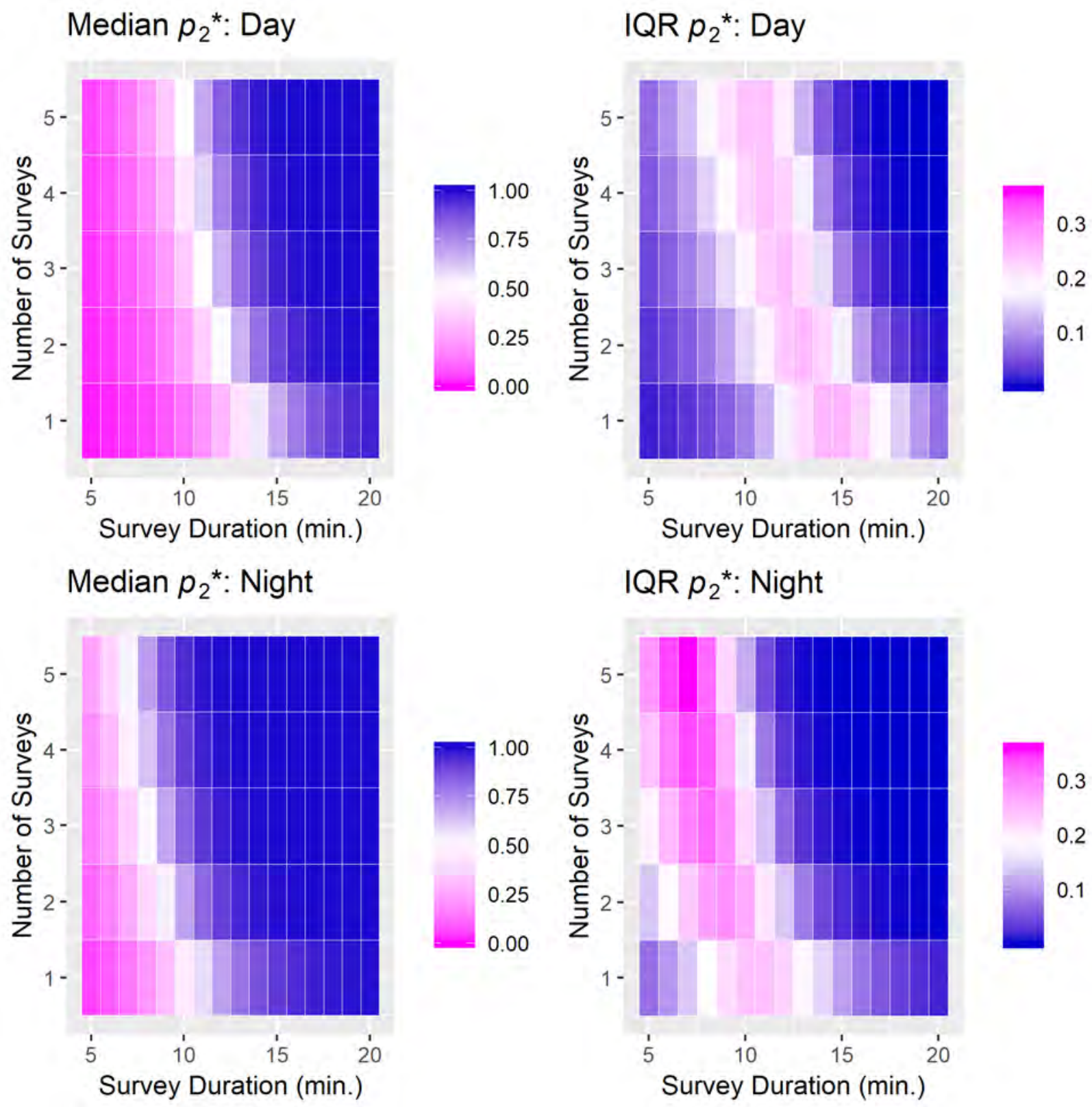

Figure 19. Cumulative detection probabilities of adult $\left(p_{2}^{*}\right)$ western toads (Anaxyrus boreas ssp.) at Hot Creek, Nevada, based on time of day, survey duration, and number of independent surveys. IOR = interquartile range. 

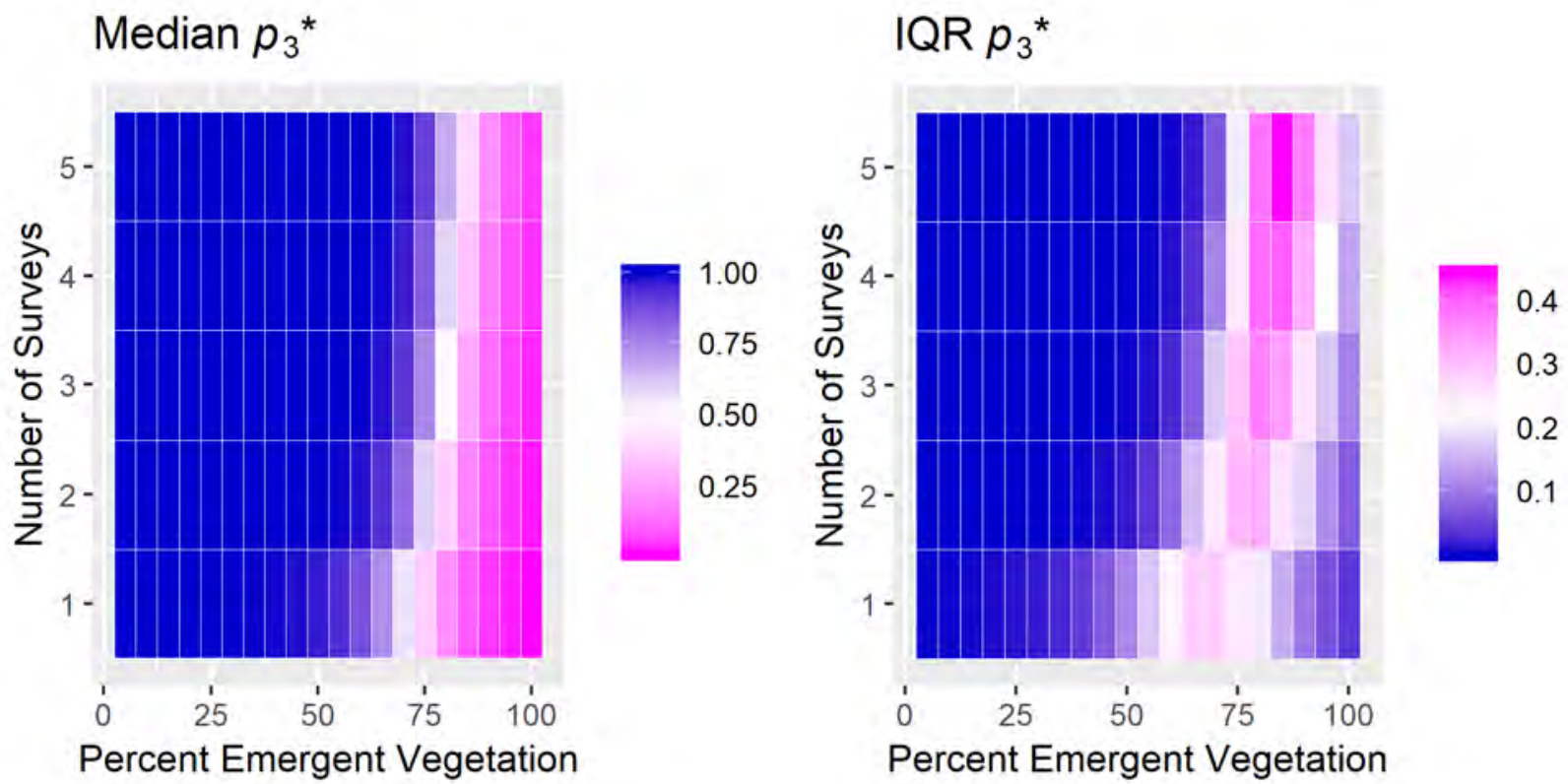

Figure 20. Cumulative detection probabilities of larval $\left(p_{3}{ }^{*}\right)$ western toads (Anaxyrus boreas ssp.) at Hot Creek, Nevada, based on emergent vegetation cover and number of independent surveys. IQR = interquartile range.

\section{Discussion}

Multistate occupancy monitoring of narrowly endemic toads of the Great Basin varied in its effectiveness across populations. In the Dixie Valley, where we had the most existing information about toad ecology, distribution, and attempted monitoring strategies, monitoring was successful, and a long-term monitoring program based on this approach is likely feasible. In the Railroad Valley, we had very little information on the distribution of the toads or their ecology; as a result, we expect that further refinements of the survey protocol will be necessary there. Nonetheless, given the extent of habitat at the Railroad Valley site, we expect that a multistate occupancy monitoring program similar to the pilot program tested will likely be a worthwhile approach at the site. Toad habitat was much more restricted at Hot Creek, and although the multi-state occupancy approach performed moderately well there, alternative approaches to monitoring, such as CMR of adults, are likely to produce more precise and useful information on population status and trends. Tailoring monitoring programs to the characteristics of the site, the ecology of the organism, and the needs of stakeholders is important to the success of monitoring to evaluate status, trends, and effects of management on wildlife populations. Therefore, we present our findings and suggestions separately for each population.

\section{Dixie Valley Toad Findings and Implications}

Dixie Valley toads were widespread in the springs, marshes, and wet meadows in Dixie Meadows. Toads were estimated to occupy the majority of the site; this was especially true in May. Combining surveys of relatively small plots over a longer time period can result in violation of the closure assumption (toads might move onto or off of plots between surveys). For example, if two plots are surveyed 1 month apart and one or more toads occupy plot A, but not plot B, in survey 1 , and toads occupy plot B, but not plot A, in survey 2 , the model could give an inflated estimate of toad occurrence, when the change is in use, rather than percent area occupied. It is for this reason that we treated the surveys conducted in April and May on the same plots as two separate plots and allowed $\psi$ to vary between survey periods. We therefore suggest that limiting the sampling period to a shorter time frame, such as conducting all surveys within a week to 10 days, is more reliable for inference about toad occurrence. Adult toad occurrence was higher in late May than late April, but the probability that reproduction occurred in a plot, given it was occupied, did not vary between survey periods. Detection probabilities for adults were higher in May than April. Mid-May is likely a good time to conduct surveys because it maximizes $p_{2}$ while ensuring that larvae are available to provide estimates of reproductive effort. Note that these suggestions are based on two survey periods conducted during spring in a single year; therefore, annual variation in environmental conditions might affect realized occurrence, reproduction, and detection probabilities. Continued monitoring will allow for revisions to the survey protocol as data accumulate. 
For all survey periods and life stages, Dixie Valley toad $p$ increased with increasing survey duration. Surveying plots longer was more efficient than surveying plots more times, and diurnal surveys for 15 minutes or longer resulted in high $p$. Nonetheless, we suggest surveying each plot multiple times for a few reasons. First, although weather conditions did not affect our detection probabilities, conditions were likely optimal across most of our surveys. Conducting multiple surveys (or alternatively, specifying conditions under which surveys should not occur) alleviates the problem of a single survey conducted under conditions leading to low $p$. Additional surveys will help to guide the conditions under which $p$ is highest and surveys most efficient. Second, it is much more time-consuming to establish the plots than to survey them. Under these conditions, it is more efficient to conduct more surveys than fewer surveys (MacKenzie and Royle, 2005) because subsequent surveys cost less than the initial survey. Finally, it is necessary to either conduct multiple surveys or record the time to initial detection of a species in a plot to quantify $p$. Without quantifying $p$, inference can be misleading. This is especially true if a plot characteristic that is positively related to $\psi$ is also negatively related to $p$ (Kéry, 2010). For example, if $\psi$ is positively related to emergent vegetation, but $p$ is negatively related to it, then without quantifying the effect of emergent vegetation on $p$, one could erroneously conclude that toads are less likely to occur in locations with higher cover of emergent vegetation. Conducting multiple surveys within a short period of time offers the greatest analytical flexibility and will increase the information about variables affecting $p$ necessary to further refine the monitoring protocol. Combining multiple surveys per plot (the metapopulation design; Kéry and Royle, 2015) and time to initial detection (Garrard and others, 2008; Halstead and others, 2018) would be particularly helpful in this regard.

Although $p_{2}$ was unaffected by the time of day a plot was surveyed, $p_{3}$ was higher during the day than at night. Given the greater ease of sampling during the day and the higher detection probabilities of larvae at that time, we suggest that springtime Dixie Valley toad surveys be diurnal.

We used $20 \mathrm{~m} \times 20 \mathrm{~m}$ square plots as our sampling units for Dixie Valley toads. The square shape corresponded to the grid placed over the site for sample selection, and square plots had several benefits. Square plots were efficient to survey by walking in rows where vegetation structure permitted. Given the importance of survey duration, if a survey was completed before a minimum specified time, one could easily resample a square plot by walking rows perpendicular to the first pass to ensure complete coverage, although if count data were to be used to estimate the abundance state of a plot then a mechanism to avoid double-counting individuals would be necessary. By marking the corners of each plot with wire flags, it was quick and easy to tell if an observed toad was on or off the plot. Nocturnal surveys, in particular, would benefit from reflective flags placed at the corners of square plots. Despite the benefits of square plots, they were very time-consuming to establish, requiring a crew of three people nearly 3 days to establish all 60 plots. An alternative to square plots that was implemented in Hot Creek and Railroad Valley was circular plots of $10-\mathrm{m}$ radius. For circular plots, one only need to locate the plot centroid and mark it, then use a tether to determine whether an observation is within or outside the plot. Although not always as straightforward to survey, circular plots greatly reduced setup time. If it is decided to use circular rather than square plots at Dixie Valley in the future, plot area should be held constant (radius $=11.28 \mathrm{~m}$ ) for comparison with this initial year of study. Our general impression is that the increased ease of sampling square plots is worth the time to establish these plots, although circular plots are a useful method for exploratory surveys used to establish a long-term sampling frame.

In summary, we suggest that monitoring surveys for Dixie Valley toads be conducted on the same $20 \mathrm{~m}$ $\times 20 \mathrm{~m}$ plots every year to explicitly model changes in state (unoccupied, occupied, occupied with evidence of reproduction) over time. May surveys would likely result in higher detection probabilities, and repeating the surveys at the same time each year is essential for evaluating changes in occurrence across years. Conducting all surveys within 5-10 days will help to minimize violations of the closure assumption for adult and larval toads. Although doubleobserver or time-to-detection techniques could further reduce violations of the closure assumption, we suggest that conducting surveys using the "metapopulation design" (Kéry and Royle, 2015) for the first few years will provide more information about variables affecting detection probability and allow appropriate constraints to be placed on surveys using these more efficient sampling protocols. A minimum survey duration of 12 minutes for three surveys per plot or 15 minutes for two surveys per plot would result in high enough $p$ for relatively precise inference about variables affecting $\psi$ and $r$ and trends in occurrence states. Diurnal surveys are both easier to implement and result in higher $p$ for larval toads and are therefore preferred for springtime surveys of Dixie Valley toads.

Occurrence of Dixie Valley toads was affected by plot conditions. In particular, $\psi$ peaked at relatively low water temperatures $\left(12-18^{\circ} \mathrm{C}\right)$ but declined substantially above $25^{\circ} \mathrm{C}$, suggesting that, at least during spring, adult Dixie Valley toads avoid the warmer water associated with the hot springs. The sensitivity of Dixie Valley toad occurrence to water temperature suggests that monitoring water temperature will be a valuable method to evaluate areas likely to be occupied by Dixie Valley toads. Changes to water temperatures in Dixie Meadows could affect the proportion of area suitable for Dixie Valley toads. Surveys in other seasons would be useful to examine whether Dixie Valley toads occur in areas with the same water temperatures throughout the active season. 
Given that Dixie Valley toads occurred in a plot, the probability that they reproduced there $(r)$ was positively associated with the percent surface area of the plot that was wetted and was highest in warm, but not hot, water (approximately $23-29^{\circ} \mathrm{C}$ ). Reproduction was particularly rare in plots with $<50$ percent wetted surface. This relationship is not surprising, given that Dixie Valley toads require water in which to deposit their eggs and for their tadpoles to develop. Larval Dixie Valley toads preferred warmer water than adults, but again did not occur in the hottest water. That Dixie Valley toad tadpoles are most likely to occur in warm water is unsurprising, given that many toad tadpoles aggregate in shallow, warm water (Beiswenger, 1977; Noland and Ultsch, 1981). Although the model predicted high $r$ even at temperatures as high as $42{ }^{\circ} \mathrm{C}$, we only observed three water temperatures $>29^{\circ} \mathrm{C}$; our confidence in a positive effect of water temperature on $r$ up to $25^{\circ} \mathrm{C}$ is relatively high, but at what temperature $r$ begins to decline is uncertain. It also is possible that Dixie Valley toad tadpoles prefer temperatures near their critical thermal maximum; in this case, a threshold response would be more appropriate than a quadratic function. Thermal preference experiments would better elucidate the relationship between Dixie Valley toad tadpole occurrence and water temperature and could identify the critical thermal maximum of these tadpoles.

\section{Railroad Valley Toad Findings and Implications}

Estimates of occupancy for western toads in the Railroad Valley were very uncertain. We observed few plots with either adult or larval toads, and because we were only able to survey each plot twice, both $\psi$ and $p$ were estimated very imprecisely. Because of the large size of the site and less information about the potential distribution of toads there, we likely included a larger sampling frame than necessary. We also chose to bypass many of the plots in the GRTS sample because of inaccessibility, usually caused by deep water. The realized GRTS sample also included many dry plots (37 of 60 , or 62 percent). Refining the sampling frame to exclude plots without toad habitat will likely increase the occurrence of toads in plots, and familiarity with the site will improve the efficiency of surveys to further refine protocols. The timing of sampling seemed appropriate, as both larvae and adult toads were observed. We expect that with more refined site selection, the multistate occupancy framework will work well for Railroad Valley toads.

The only variable we examined for $\psi$ and $r$ for Railroad Valley toads, percent wetted surface, was not found to affect either parameter. This was likely because of low statistical power to detect effects, rather than the absence of an effect. As with Dixie Valley toads, $p$ of Railroad Valley toad larvae and adults was positively related to survey duration, with surveys of 15-20 minutes resulting in high median $p$. Larval Railroad Valley toad $p_{3}$ also was higher during the day than at night. Conducting three diurnal surveys of at least 15 minutes duration in each plot, or two diurnal surveys of at least 20 minutes duration in each plot, will likely result in relatively precise inference about Railroad Valley toad occurrence. Late May is likely a good time to monitor this population because both larvae and adults are present then.

\section{Hot Creek Toad Findings and Implications}

Western toads were widespread along the surveyed section of Hot Creek. None of the variables we evaluated were related to $\psi$ for Hot Creek toads, but adult toads seemed to concentrate along a segment of the creek at night. Because of this aggregation, the relative ease of observing and capturing toads, and the limited availability of moisture in the surrounding landscape, CMR studies of adult toads to estimate absolute abundance or density is likely possible at Hot Creek.

Unlike $\psi, r$ (the probability of reproduction) of Hot Creek toads was affected by percent wetted surface of the plot and percent cover of emergent vegetation. In particular, $r$ was highest at moderately high cover (65-90 percent) of emergent vegetation and in plots with a higher percentage of their surface wetted. Although we were able to estimate these relationships, we caution that few plots (3) had observations of larvae, so our sample size and the precision with which these effects were estimated were limited. Nonetheless, an increase in $r$ with percent surface area wetted aligns with expectations because tadpoles cannot occur in plots without water. With increased sampling effort, more complex relationships, such as a ceiling on $r$ in cells with abundant water, could be implemented (Hobbs and Hooten, 2015; Rose and others, 2018).

A further limitation on our inference at Hot Creek was the relatively small amount of suitable habitat on public land. Our initial selection of plots inadvertently included private land. Although the rancher was amenable to our sampling, we suggest that future monitoring be limited to public land. Because aquatic habitat on public land is fairly limited, CMR of adults where they concentrate in aquatic habitats will likely be effective, although it will likely be necessary to account for temporary emigration (Kendall and others, 1997; Schmidt and others, 2002) in CMR models to account for toads moving off-site. 
Adult Hot Creek toad detection probabilities were very low during the day but increased approximately fivefold at night. A resident herd of wild horses that grazed and drank at the site resulted in disturbance and reduced cover; observations at the site suggested that adult toads might have spent their days in safe retreats among the scrub vegetation, coming out at night to rehydrate and forage. As with the other populations, increasing survey duration increased $p$ for adult toads, and nocturnal survey durations of 15 minutes or more resulted in high $p_{2}$. Unlike adults and larvae from other populations, survey duration did not affect $p$ of larval Hot Creek toads; instead, $p_{3}$ was negatively related to the amount of emergent vegetation cover on a plot. Detection probabilities of larval toads were low on plots with $>70$ percent emergent vegetation cover. Longer or more surveys of plots with extensive emergent vegetation cover are likely warranted.

Based on our observations of toad behavior and the habitat at Hot Creek, we suggest nocturnal CMR surveys of adult Hot Creek toads in June or July, after most threat of snowfall has passed. General diurnal visual encounter surveys to confirm that larvae are present would indicate whether breeding occurred in a given year. If more detailed information about larval distribution and habitat relationships is desired, continued occupancy monitoring of larvae is suggested.

\section{Summary} Service.

Prepared in cooperation with the U.S. Fish and Wildlife

\section{Dixie Valley Toads}

- Multistate occupancy sampling and analysis were well-suited to meeting monitoring objectives for Dixie Valley toads.

- Adult Dixie Valley toad occurrence was highest at relatively cool water temperatures between 12 and $18{ }^{\circ} \mathrm{C}$.

- Dixie Valley toad reproduction was positively related to the percent surface of the plot that was wetted and was very low below 50 percent wetted surface. Dixie Valley toad tadpoles were most likely to occur in warm water $\left(20-30^{\circ} \mathrm{C}\right)$ but not at the hot spring heads.

- Detection probabilities for adult Dixie Valley toads increased with increasing survey duration and were very high for surveys of 15 minutes or more. Adult detection probabilities increased slightly with increasing cover of emergent vegetation.

- Larval Dixie Valley toad detection probabilities also were positively related to survey duration, with surveys of 10 minutes or more resulting in very high $p$. Diurnal surveys were more effective for detecting Dixie Valley toad larvae than nocturnal surveys. Larval detection probabilities were negatively related to emergent vegetation.

- Monitoring implications: Monitoring the same plots annually in mid-May, with either two diurnal surveys of at least 15 minutes each or three diurnal surveys of at least 12 minutes each, will likely provide relatively precise estimates of $\psi$ and $r$. Multistate occupancy modeling with further surveys over multiple years will allow examination of the effect of the environmental variables on these population states and trends in these population states over time.

\section{Toads in the Railroad Valley}

- With a refined sampling frame and both longer and more surveys, multistate occupancy sampling will likely be effective for Railroad Valley toads.

- Because relatively few plots contained aquatic habitat and we conducted few surveys per plot, we had few detections of adult or larval Railroad Valley toads. Thus, current inference about occurrence has low precision.

- Survey duration was positively related to $p$ for both adults and larvae, and diurnal surveys were more effective than nocturnal surveys for larvae. Surveys of 15 minutes or longer resulted in relatively high $p$.

- Monitoring implications: Monitoring a more refined (to include more shallow aquatic habitat) selection of 60 plots annually in late May, with either two diurnal surveys of at least 20 minutes each or three diurnal surveys of at least 17 minutes each, will likely provide relatively precise estimates of $\psi$ and $r$. Multistate occupancy modeling with further surveys over multiple years will allow examination of the effect of the environmental variables on these population states and trends in these population states over time.

\section{Toads at Hot Creek}

- Adult Hot Creek toads were widespread, but occurrence was unrelated to any of the examined variables.

- Larval Hot Creek toads were more likely to occur in plots with moderate to high emergent vegetation cover and a higher proportion of their surface area wetted. These relationships were estimated imprecisely because of a small sample of plots with observed larvae. 
- Adult Hot Creek toad detection probabilities were 5 times higher at night than during the day and increased with increasing survey duration. For adult Hot Creek toad occupancy, three nocturnal surveys of a minimum of 12 minutes each or two nocturnal surveys for a minimum of 15 minutes each are suggested if a multistate occupancy approach is implemented at the site.

- Larval Hot Creek toad detection probability was negatively affected by the percent cover of emergent vegetation, so greater effort will likely be necessary in heavily vegetated plots to achieve precise estimates of $r$.

- Monitoring implications: Because of the concentration of adult toads along a segment of stream and their high detectability there, we suggest that CMR studies, which provide information on absolute abundance, density, survival, recruitment, and population growth rate, be implemented on a trial basis at Hot Creek in June to avoid late season snowfall. Diurnal visual encounter surveys could be used to verify that the population is reproducing; if quantitative information about trends in reproduction is desired, diurnal occupancy surveys, such as those conducted in this study, could be continued.

\section{References Cited}

Beiswenger, R.E., 1977, Diel patterns of aggregative behavior in tadpoles of Bufo americanus, in relation to light and temperature: Ecology, v. 58, no. 1, p. 98-108, https://doi.org/10.2307/1935111.

Denwood, M.J., 2016, runjags-An R package providing interface utilities, model templates, parallel computing methods and additional distributions for MCMC Models in JAGS: Journal of Statistical Software, v. 71, no. 9, p. 1-25, https://doi.org/10.18637/jss.v071.i09.

Forrest, M.J., Stiller, J., King, T.L., and Rouse, G.W., 2017, Between hot rocks and dry places-The status of the Dixie Valley toad: Western North American Naturalist, v. 77, no. 2, p. 162-175, https://doi.org/10.3398/064.077.0204.

Garrard, G.E., Bekessy, S.A., McCarthy, M.A., and Wintle, B.A., 2008, When have we looked hard enough? A novel method for setting minimum survey effort protocols for flora surveys: Austral Ecology, v. 33, no. 8, p. 986-998, https://doi.org/10.1111/j.1442-9993.2008.01869.x.

Gelman, A., 2006, Prior distributions for variance parameters in hierarchical models: Bayesian Analysis, v. 1, no. 3, p. 515-534, https://doi.org/10.1214/06-BA117A.
Gelman, A., and Rubin, D.B., 1992, Inference from iterative simulation using multiple sequences: Statistical Science, v. 7, no. 4, p. 457-472, https://doi.org/10.1214/ss/1177011136.

Gordon, M.R., Simandle, E.T., and Tracy, C.R., 2017, A diamond in the rough desert shrublands of the Great Basin in the Western United States: A new cryptic toad species (Amphibia: Bufonidae: Bufo (Anaxyrus)) discovered in Northern Nevada: Zootaxa, v. 4290, no. 1, p. 123-139, https://doi.org/10.11646/zootaxa.4290.1.7.

Halstead, B.J., Kleeman, P.M., and Rose, S., 2018, Timeto-detection occupancy modeling-An efficient method for analyzing the occurrence of amphibians and reptiles: Journal of Herpetology, v. 52, no. 4, p. 415-424, https://doi.org/10.1670/18-049.

Hobbs, N.T., and Hooten, M.B., 2015, Bayesian models-A statistical primer for ecologists: Princeton, N.J., Princeton University Press, $320 \mathrm{p}$.

Kendall, W.L., Nichols, J.D., and Hines, J.E., 1997, Estimating temporary emigration using capture-recapture data with Pollock's robust design: Ecology, v. 78, no. 2, p. 563-578.

Kéry, M., 2010, Introduction to WinBUGS for Ecologists-A Bayesian approach to regression, ANOVA, mixed models and related analyses: Burlington, Mass., Academic Press, $320 \mathrm{p}$.

Kéry, M., and Royle, J.A., 2015, Applied hierarchical modeling in ecology: Analysis of distribution, abundance, and species richness in R and BUGS. Volume 1-Prelude and static models: London, Academic Press, 808 p.

Kéry, M., and Schaub, M., 2012, Bayesian population analysis using WinBUGS - A hierarchical perspective: Waltham, Mass., Academic Press, 554 p.

Kincaid, T.M., and Olsen, A.R., 2016, spsurvey-Spatial survey design and analysis.

Kruschke, J.K., 2015, Doing Bayesian Data Analysis-A Tutorial with R, JAGS, and Stan: London, Academic Press, $776 \mathrm{p}$.

Kuo, L., and Mallick, B., 1998, Variable selection for regression models: Sankhya Series B, v. 60, no. 1, p. 65-81.

Link, W.A., and Barker, R.J., 2010, Bayesian inference-With ecological applications: London, Academic Press, 354 p.

MacKenzie, D.I., and Royle, J.A., 2005, Designing occupancy studies-General advice and allocating survey effort: Ecology, v. 42, p. 1105-1114. 
Nichols, J.D., Hines, J.E., Mackenzie, D.I., Seamans, M.E., and Gutiérrez, R.J., 2007, Occupancy estimation and modeling with multiple states and state uncertainty: Ecology, v. 88, no. 6, p. 1395-1400, https://doi.org/10.1890/06-1474.

Noland, R., and Ultsch, G.R., 1981, The roles of temperature and dissolved oxygen in microhabitat selection by the tadpoles of a frog (Rana pipiens) and a toad (Bufo terrestris): Copeia, v. 1981, no. 3, p. 645-652.

Plummer, M., 2017, JAGS 4.3.0 User Manual: Available at: https://sourceforge.net/projects/mcmc-jags/files/ Manuals/4.x/jags_user_manual.pdf/download (accessed 28 May 2019).

R Core Team, 2017, R: A language and environment for statistical computing: Vienna, Austria, R Foundation for Statistical Computing.

Rose, J.P., Wylie, G.D., Casazza, M.L., and Halstead, B.J., 2018, Integrating growth and capturemark-recapture models reveals size-dependent survival in an elusive species: Ecosphere, v. 9, no. 8, e02384, https://doi.org/10.1002/ecs2.2384.

Schmidt, B.R., Schaub, M., and Anholt, B.R., 2002, Why you should use capture-recapture methods when estimating survival and breeding probabilities - On bias, temporary emigration, overdispersion, and common toads: Amphibia-Reptilia, v. 23, no. 3, p. 375-388, https://doi.org/10.1163/15685380260449234.

Stevens, D.L., Jr., and Olsen, A.R., 2004, Spatially balanced sampling of natural resources: Journal of the American Statistical Association, v. 99, no. 465, p. 262-278, https://doi.org/10.1198/016214504000000250. 
For more information concerning the research in this report, contact the Director, Western Ecological Research Center

U.S. Geological Survey

3020 State University Drive East

Sacramento, California 95819

https://www.usgs.gov/centers/werc 


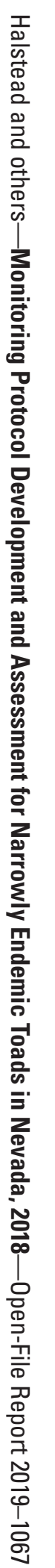

